\title{
Feature-Parameter-Criterion for Predicting Lean Blowout Limit of Gas Turbine Combustor and Bluff Body Burner
}

\author{
Hongtao Zheng, ${ }^{1}$ Zhibo Zhang, ${ }^{1}$ Yajun $\mathrm{Li}^{2}{ }^{2}$ and Zhiming Li \\ ${ }^{1}$ College of Power and Energy Engineering, Harbin Engineering University, Harbin 150001, China \\ ${ }^{2}$ China Shipbuilding Industry Corporation, No. 703 Research Institute, Harbin 150078, China \\ Correspondence should be addressed to Hongtao Zheng; zhenghongtao9000@163.com
}

Received 25 June 2013; Accepted 22 September 2013

Academic Editor: Tirivanhu Chinyoka

Copyright (c) 2013 Hongtao Zheng et al. This is an open access article distributed under the Creative Commons Attribution License, which permits unrestricted use, distribution, and reproduction in any medium, provided the original work is properly cited.

\begin{abstract}
Lean blowout (LBO) limit is one of the most important combustor parameters. A new method named Feature-Parameter-Criterion (FPC) for predicting LBO limit has been put forward in the present work. A computational fluid dynamics (CFD) software FLUENT has been used to simulate the process of LBO of gas turbine combustor and bluff body burner. And "M" flame has been proposed as the portent for predicting lean blowout of gas turbine combustor. Effects of flow velocity, air temperature, droplet averaged-diameter, and flow distribution between swirlers and primary holes on the LBO limit of gas turbine combustor have been researched by use of Feature-Parameter-Criterion in this paper. The effects of fuel air mixture velocity and different structures on bluff body LBO limit have also been analyzed in the present work by use of FPC. The results show that the simulation of LBO limit based on FPC is in good agreement with the experiment data (the errors are about 5\%) and this method is reliable for engineering applications.
\end{abstract}

\section{Introduction}

Gas turbine is one of the most important fluid machineries in the engineering field, and bluff body burner is widely used in engine combustors to stabilize flames [1]. There are many core problems, such as heat and mass transfer, $\mathrm{CO}_{2}$ and $\mathrm{NO}_{X}$ emission, and lean blowout, to be researched. Due to increasingly stringent emission requirements, modern gas turbine combustors usually work under lean operating conditions [2] for lowering combustion temperature and reducing the production rate of $\mathrm{NO}_{X}$. The operation near the lean blowout (LBO) limit, however, may result in undesirable combustion characteristics, such as flashback and combustion instabilities due to the partial flame extinction and dynamic fluctuations of heat release rate, which will lead to low combustion efficiency and poor operability of the combustor.

Experimental studies on combustor performance of gas turbine are essential, but huge experimental measurements are expensive and time consuming. Numerical methods provide a reasonable approach for combustor performance prediction, heat and mass transfer process, chemical reaction recurrence, and transient response $[3,4]$. At the same time, some advanced mathematical models $[5,6]$ have been presented. In addition, the Reynolds-Averaged Navier-Stokes (RANS) based approach has been widely used in device design and optimization due to its lower requirement in computational spending and its acceptable precision prediction of time-averaged flow properties $[7,8]$. RANS approach can provide quality instruction for combustor design [9]. But for lean blowout limit predicting, advanced method should be used to match up with RANS approach.

On predicting lean blowout in gas turbine combustor, there are three main methods at present: experimental research method, empirical formula method, and numerical simulation method. In experimental research, Marinov et al. [2, 10-12] and Yuan et al. [13-16] did effective work in their respective fields. But the experimental research method needs high-precision measuring equipment and the cost is high. Being subject to experiment condition, it would unlikely obtain inner parameters distribution and changes law in gas turbine combustor. In empirical formula, A. H. Lefebvre and D. R. Ballal Lefebvre [17] and Meller [18] proposed the semiempirical formula based on heat balance model and the characteristic time model. Rizk and Mongia [19, 20] proposed the multidimensional empirical analysis method. Rizk and Mongia [21] revised Lefebvre's 
semiempirical formula and put it into computational fluid dynamics field. The advantages of empirical formula method are high-precision and convenience, but they are only aimed at certain combustion and bring poor universalness. In numerical simulation, Kim et al. [22] researched the lean blowout limit of bluff body burner with large eddy simulation technology, and some of the works were mainly focused on bluff body stabilized flames as summarized in a recent review by Shanbhogue et al. [23]. Kumaran and Shet found that the LBO limit depends on aeroengine parameters including swirl number [24]. Furthermore the LBO limit can be extended to addition of hydrogen $[25,26]$. Cai et al. proposed the fuel steady stepwise method to predict the LBO limit, and predictions were in agreement with corresponding experimental data [27]. However, most of researches did not propose appropriate criterion for predicting lean blowout limit. CAI Wenxiang's method was only aimed at annular combustor and could not be used in other combustor style.

A new method named Feature-Parameter-Criterion (FPC) for predicting LBO limit of gas turbine combustor and bluff body burner has been put forward in this paper. A new parameter named as feature-parameter, detailed prediction principle, and lean blowout process have been shown firstly. And then comparison between numerical simulation results and experimental data has been made to test and verify the accuracy of Feature-Parameter-Criterion.

\section{Geometry and Mathematical Models}

The present work is based on an annular combustor of gas turbine and a type of bluff body burner.

The geometry of annular combustor which burn oil C7H16 has been shown in Figure 1. It is composed of diffuser, swirler, primary holes, nozzle, cooling holes, and flame tube. The length of diffuser is $150 \mathrm{~mm}$, and the length and diameter of flame tube are separately $250 \mathrm{~mm}$ and $100 \mathrm{~mm}$. There are 10 primary holes with $10 \mathrm{~mm}$-diameter for each and 40 cooling holes with $8 \mathrm{~mm}$-diameter for each. Air is supplied axially through "Air-inlet" (1522 $\mathrm{mm}^{2}$ for area) and divided into two parts: one part of air passes over the swirler to help atomizing fuel and form a central recirculation zone (CRZ) in the downstream of swirler; the other part of air flows into the primary holes and cooling holes. The purpose is forming combustion flow field and protecting flame tube. Combustion occurs within the flame tube and all the emissions discharge through outlet. In order to improve grid quality and save the calculation resources, periodic boundary condition and Hexa-Core grid technology are used in this paper. The middle section of the grid is shown in Figure 2.

Boundary conditions of annular combustor are as follows:

operation pressure: $4.2 \mathrm{MPa}$;

air-inlet:

velocity: $50 \mathrm{~m} / \mathrm{s}-90 \mathrm{~m} / \mathrm{s}$, temperature: $285 \mathrm{~K}-530 \mathrm{~K}$;

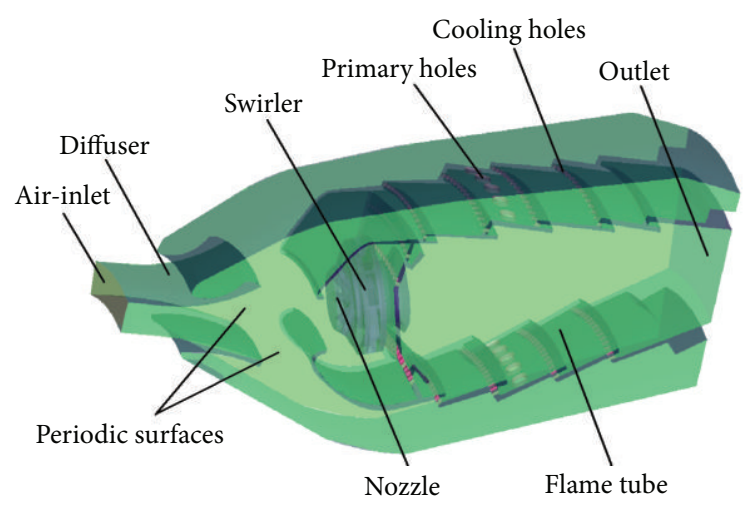

FIGURE 1: Geometry of annular combustor.

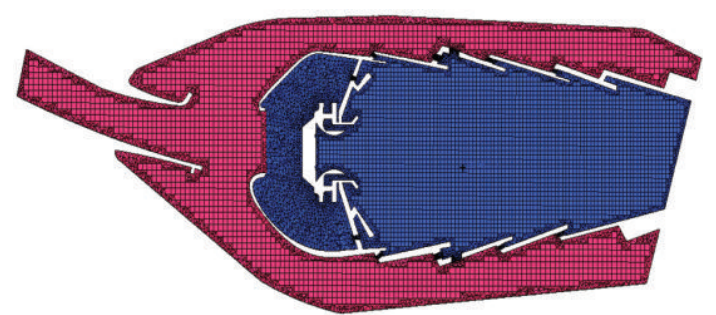

FIgURE 2: The middle section of the grid of annular combustor.

nozzle:

fuel: liquid kerosene (C7H16),

fuel air ratio: 0.00415-0.0187,

temperature: $300 \mathrm{~K}$,

droplet averaged-diameter: $30 \mu \mathrm{m}-160 \mu \mathrm{m}$; the oil-fired droplet follows Rosin-Rammler (R-R) Function;

outlet: pressure outlet;

Wall: one group of wall is periodic, adiabatic boundary, and others are no-slip, adiabatic boundary.

With reference to [28] the structure of axisymmetric and coaxial bluff body is used in this paper. The central mixture (air + liquefied petroleum gas (LPG)) is supplied axially through a central axial tube with $4.9 \mathrm{~mm}$ diameter for single hole. The coflowing (coaxial) air passes over disk stabilizer with diameter of $55 \mathrm{~mm}$ or conical bluff body with the angle of 30 degree-90 degree. The disk stabilizer is placed into the interior of a burner pipe with the diameter of $82 \mathrm{~mm}$. In this way, the edge of the central axial tube and the burner pipe can be ensured to be in the same vertical plane. The burner is confined in a combustor of $152.4 \mathrm{~mm}$ diameter by a cooling jacket. The geometrical structure of bluff body burner is shown in Figure 3. To improve the calculation accuracy, block structure grid technology is used for bluff body burner. The middle section of the grid is shown in Figure 4. 


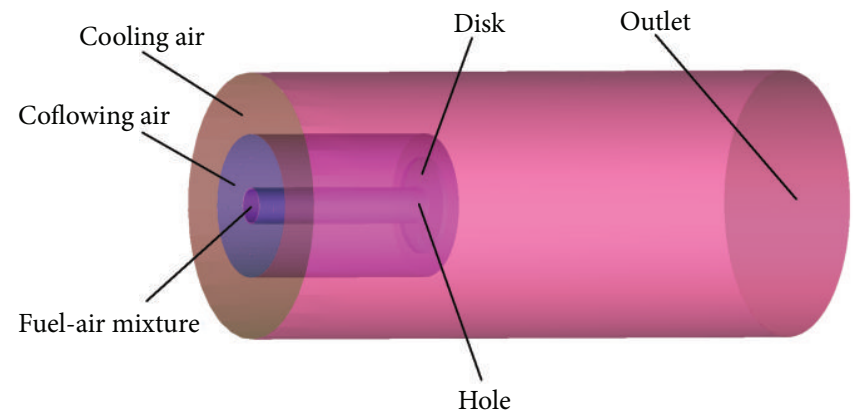

FIGURE 3: Geometry of bluff body burner.

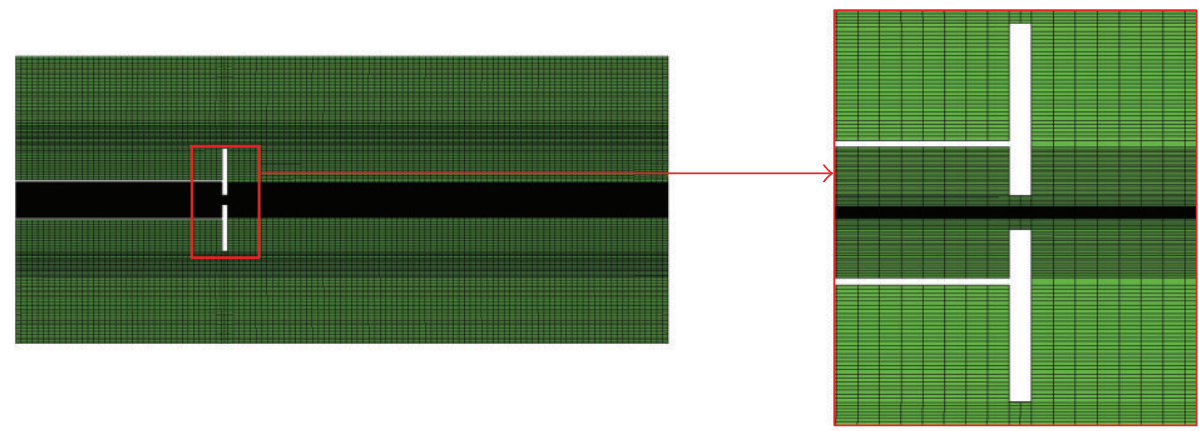

FIGURE 4: The middle section of the grid of bluff body burner.

Boundary conditions of bluff body burner are as follows: operation pressure: $0.1 \mathrm{MPa}$;

fuel air mixture:

velocity: $23.8 \mathrm{~m} / \mathrm{s}-42.3 \mathrm{~m} / \mathrm{s}$,

temperature: $300 \mathrm{~K}$;

air + liquefied petroleum gas (LPG);

Coflowing air:

velocity: $4.8 \mathrm{~m} / \mathrm{s}$,

temperature: $300 \mathrm{~K}$;

cooling air:

velocity: $4.8 \mathrm{~m} / \mathrm{s}$,

temperature: $300 \mathrm{~K}$;

outlet: pressure outlet;

wall: the maximum cylinder wall is pressure outlet; others are no-slip, adiabatic boundary.

In combustion flows, conservation equations for mass, momentum, energy, species, state, and turbulence are solved. All the primary equations which are used in this paper are as follows (ignore radiation and gravitation).

Mass conservation equation:

$$
\nabla \cdot(\rho \vec{V})=S_{m}
$$

Momentum conservation equation:

$$
\nabla \cdot(\rho \overrightarrow{V V})=-\nabla p+\nabla \cdot \tau+\vec{F} .
$$

Energy conservation equations:

$$
\begin{aligned}
\nabla \cdot(\rho \vec{V} E)= & \nabla \cdot\left(-\vec{q}-p \vec{V}+\tau \cdot \vec{V}-\sum_{i=1}^{N_{S}} h_{i} \overrightarrow{J_{i}}\right) \\
& +S_{h}+q_{p} .
\end{aligned}
$$

Species transport equation:

$$
\nabla \cdot\left(\rho \vec{V} m_{i}\right)=-\nabla \cdot \overrightarrow{J_{i}}+R_{i}+Q_{i}
$$

Realizable $k-\varepsilon$ models:

$$
\begin{gathered}
\nabla \cdot(\rho \vec{V} k)=\nabla \cdot\left(\Gamma_{k} \nabla k\right)+G_{k}+G_{b}-\rho \varepsilon-Y_{k}+S_{k}, \\
\nabla \cdot(\rho \vec{V} \varepsilon)=\nabla \cdot\left(\Gamma_{\varepsilon} \nabla \varepsilon\right)+\rho C_{1} S \varepsilon-\rho C_{2} \frac{\varepsilon^{2}}{k+\sqrt{v \varepsilon}}
\end{gathered}
$$



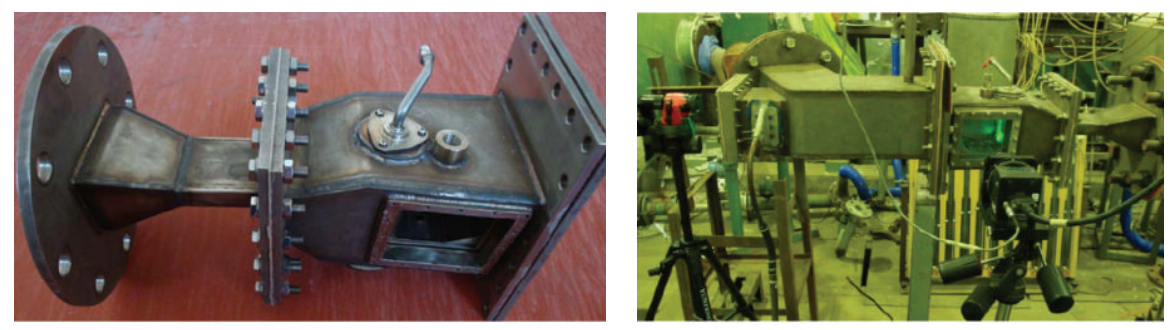

FIgURE 5: Experimental apparatus of gas turbine combustor.

RNG $k-\varepsilon$ models:

$$
\begin{aligned}
\frac{\partial}{\partial x_{i}}\left(\rho k u_{i}\right)= & \frac{\partial}{\partial x_{j}}\left(\alpha_{k} \mu_{\mathrm{eff}} \frac{\partial k}{\partial x_{j}}\right) \\
& +G_{k}+G_{b}-\rho \varepsilon-Y_{M}+S_{k} \\
\frac{\partial}{\partial x_{i}}\left(\rho \varepsilon u_{i}\right)= & \frac{\partial}{\partial x_{j}}\left(\alpha_{\varepsilon} \mu_{\mathrm{eff}} \frac{\partial \varepsilon}{\partial x_{j}}\right) \\
& +C_{1 \varepsilon} \frac{\varepsilon}{k}\left(G_{k}+C_{3 \varepsilon} G_{b}\right) \\
& -C_{2 \varepsilon} \rho \frac{\varepsilon^{2}}{k}-R_{\varepsilon}+S_{\varepsilon} .
\end{aligned}
$$

Eddy-dissipation (ED) combustion model was used to simulate the combustion chemical reaction of gas turbine combustor in this paper. The net rate of production of species $i$ due to reaction $R_{i, r}$ is given by the smaller of the two expressions below:

$$
\begin{gathered}
R_{i, r}=v_{i . r}^{\prime} M_{w, i} A \rho \frac{\varepsilon}{k} \min R\left(\frac{Y_{R}}{v_{R, r}^{\prime} M_{w \cdot R}}\right), \\
R_{i, r}=v_{i . r}^{\prime} M_{w, i} A B \rho \frac{\varepsilon}{k} \frac{\sum p Y_{P}}{\sum_{j}^{N} v_{j, r}^{\prime \prime} M_{w, j}} .
\end{gathered}
$$

Cone injection and Rosin-Rammler (R-R) Function were used to simulate the fuel droplet diameter distribution of C7H16 in annular combustor. R-R Function of oil atomization characteristic is as follows:

$$
R=\exp \left[-\left(\frac{d}{\bar{d}}\right)^{h}\right]
$$

\section{Validations of Mathematical Models}

In order to verify the accuracy of mathematical models which were used in this paper, the comparison has been done with experiment results. This paper and [28, 29] have the same combustor structure and condition parameters. Experimental apparatus of [29] has been shown in Figure 5.

3.1. Validations of Independence of Grid Size. In numerical simulations, firstly the study on grid independence is performed to determine the best grid with the highest accuracy.
For the annular combustor of the gas turbine, Table 1 shows 9 kinds of grid size ranging from $2.1 \mathrm{~mm}$ to $4.0 \mathrm{~mm}$ (the number of the grid varies from $4.4 e+06$ to $2.1 e+$ 06). The FLUENT is used for monitoring the outlet average temperature $\left(T_{\text {out }}\right)$ and combustion efficiency $(\eta)$ in order to verify the grid size accuracy. Table 1 indicates that the change rate of outlet temperature is only $0.88 \%$ when grid size is $2.6 \mathrm{~mm}$ and the change rate of combustion efficiency is only $0.81 \%$ when grid size is $2.9 \mathrm{~mm}$. With integrated consideration of these two parameters, the grid size of $2.6 \mathrm{~mm}$ is chosen in this paper.

For bluff body burner, Table 2 shows 7 kinds of grid size range which range from $1.1 \mathrm{~mm}$ to $3.0 \mathrm{~mm}$ (the grid number varies from $7.82 e+05$ to $5.69 e+06)$ in this paper. Outlet average temperature $\left(T_{\text {out }}\right)$ and average velocity of a special point (it is in the axis, and the distance between it and disk is $40 \mathrm{~mm}, V_{40}$ ) have been monitored by using FLUENT to verify the accuracy of grid size. From the table, it can conclude that grid size $\Delta=1.7 \mathrm{~mm}$ should be the best chosen in this paper.

\subsection{Validations of Turbulence Combustion Model}

3.2.1. Validations for Annular Combustor of Gas Turbine. To improve the accuracy of simulation, at first, the turbulence combustion models should be validated.

Fuel oxidation was modeled by one-step global reaction:

$$
\mathrm{C}_{7} \mathrm{H}_{16}+11 \mathrm{O}_{2} \longrightarrow 7 \mathrm{CO}_{2}+8 \mathrm{H}_{2} \mathrm{O}
$$

The reaction rate proposed by fluent database according to Arrhenius is as follows:

$$
\begin{aligned}
\omega=\frac{d\left[\mathrm{C}_{7} \mathrm{H}_{16}\right]}{d t}= & -2.868 \times 10^{-9} e^{-15107 / T} \\
& \times\left[\mathrm{C}_{7} \mathrm{H}_{16}\right]^{0.25}\left[\mathrm{O}_{2}\right]^{1.5}
\end{aligned}
$$

Figure 6 shows the comparison between the results of different turbulence models and experiment data. More specifically, turbulence models including realizable $k$-epsilon model (RKE), RNG $k$-epsilon model (RNG), Reynolds stress model (RSM), and large eddy simulation model (LES) are chosen to validate the accuracy. It indicates that the curves by using of RNG $k$-epsilon model and LES model have the same trend as from experimental data. When $x<75 \mathrm{~mm}$, RNG $k$-epsilon model can get better results. And when $x>150 \mathrm{~mm}$, the error between the numerical result and the experiment data by using LES model is extremely small. Under other conditions, the two kinds of models can obtain almost same curves. 
TABLE 1: Grid size independence validation of annular combustor.

\begin{tabular}{|c|c|c|c|c|c|}
\hline Grid size $/ \mathrm{mm}$ & $T_{\text {out }} / \mathrm{K}$ & Rate of change $/ \%$ & $\eta$ & Rate of change $/ \%$ & Grid amount \\
\hline 4 & 1373.23 & - & 0.97 & - & 2100314 \\
\hline 3.7 & 1486.62 & $8.26 \%$ & 0.985 & $1.55 \%$ & 2447927 \\
\hline 3.5 & 1374.54 & $7.54 \%$ & 0.97 & $1.52 \%$ & 2890137 \\
\hline 3.3 & 1457.32 & $6.02 \%$ & 0.982 & $1.24 \%$ & 3143522 \\
\hline 3.1 & 1399.51 & $3.97 \%$ & 0.993 & $1.12 \%$ & 3325334 \\
\hline 2.9 & 1372.03 & $1.96 \%$ & 0.985 & $0.81 \%$ & 3605722 \\
\hline 2.6 & 1360.02 & $0.88 \%$ & 0.978 & $0.71 \%$ & 3891140 \\
\hline 2.3 & 1371.92 & $0.87 \%$ & 0.984 & $0.61 \%$ & 4020562 \\
\hline 2.1 & 1380.54 & $0.63 \%$ & 0.987 & $0.30 \%$ & 4415871 \\
\hline
\end{tabular}

TABLE 2: Grid size independence validation of bluff body burner.

\begin{tabular}{|c|c|c|c|c|c|}
\hline Grid size/mm & $T_{\text {out }} / \mathrm{K}$ & Rate of change/\% & $V_{40}$ & Rate of change/\% & Grid amount \\
\hline 3.0 & 851.07 & - & 23.28 & - & 782198 \\
\hline 2.5 & 865.31 & $1.67 \%$ & 24.97 & $7.26 \%$ & 1365165 \\
\hline 2.2 & 842.63 & $2.62 \%$ & 25.49 & $2.08 \%$ & 1965144 \\
\hline 2.0 & 835.51 & $0.84 \%$ & 25.23 & $1.02 \%$ & 2496055 \\
\hline 1.7 & 830.24 & $0.63 \%$ & 25.46 & $0.91 \%$ & 3325334 \\
\hline 1.4 & 834.97 & $0.57 \%$ & 25.31 & $0.59 \%$ & 4047064 \\
\hline 1.1 & 831.26 & $0.44 \%$ & 25.17 & $0.55 \%$ & 5693193 \\
\hline
\end{tabular}

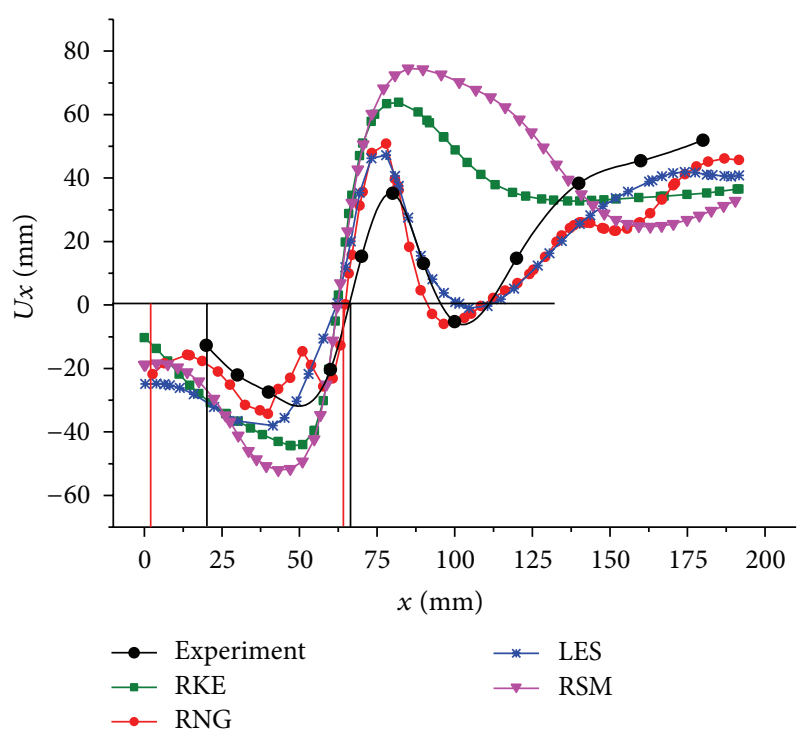

FIgURE 6: Profile of $U x$ of cold field in the middle axis.

Figure 7 shows the comparison between the results of different combustion models and experiment data. More specifically, combustion models include probability density function model (PDF), eddy-dissipation model (ED), eddy-dissipation concept model (EDC), and finite-rate/eddydissipation model (Finite-Rate/ED). From the figure it can be concluded that when $x<75 \mathrm{~mm}$, only ED model could fit the experiment data. When $x>75 \mathrm{~mm}$, the simulated results with all combustion models are the same. As known to all, the character of central recirculation zone (CRZ) is $U x<0$.

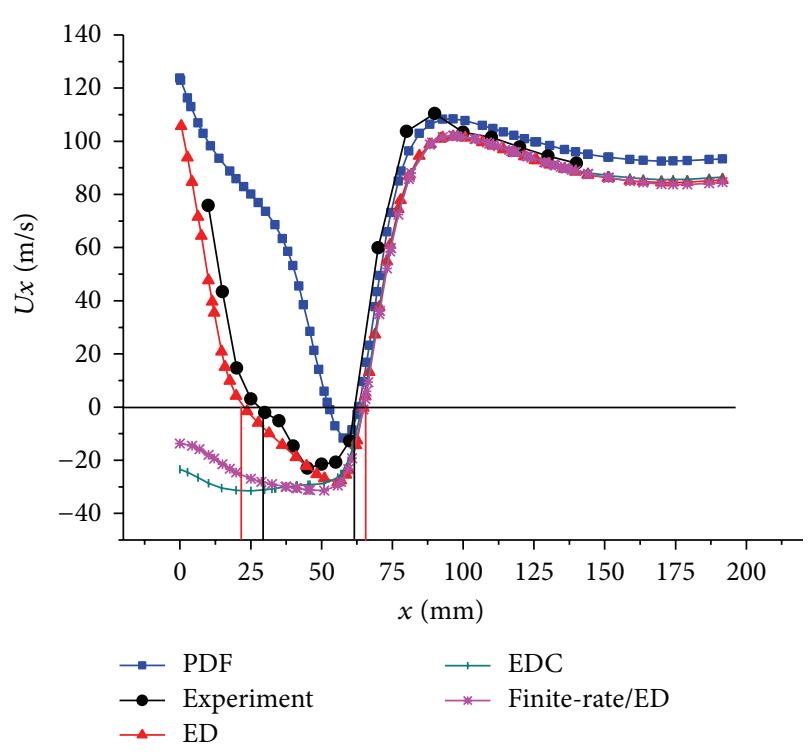

FIgURE 7: Profile of $U x$ of combustion field in the middle axis.

The region of CRZ is also shown in Figure 6. It indicates that the region of CRZ simulated with ED is almost same as experiment data.

As shown above, it can be concluded that RNG $k$ epsilon turbulence model and ED combustion model are the best choice in numerical simulation of gas turbine annular combustor in this paper.

3.2.2. Validations for Bluff Body Burner. In the numerical simulation of bluff body burner, four different turbulence 


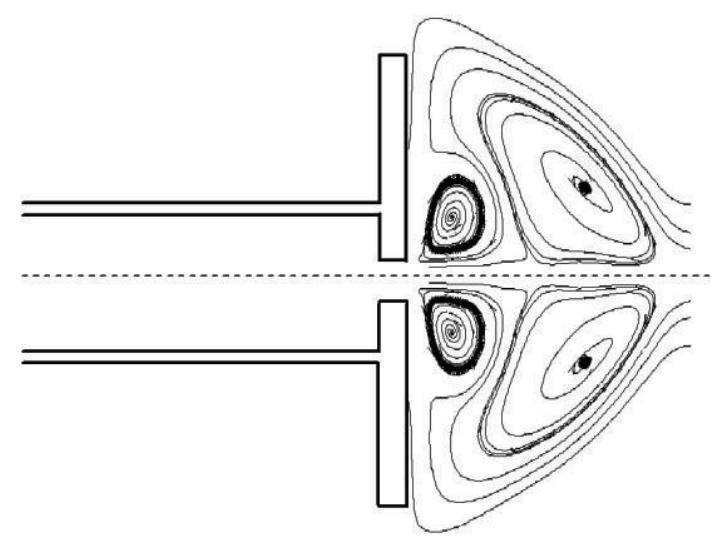

(a) Realizable $k$-epsilon model

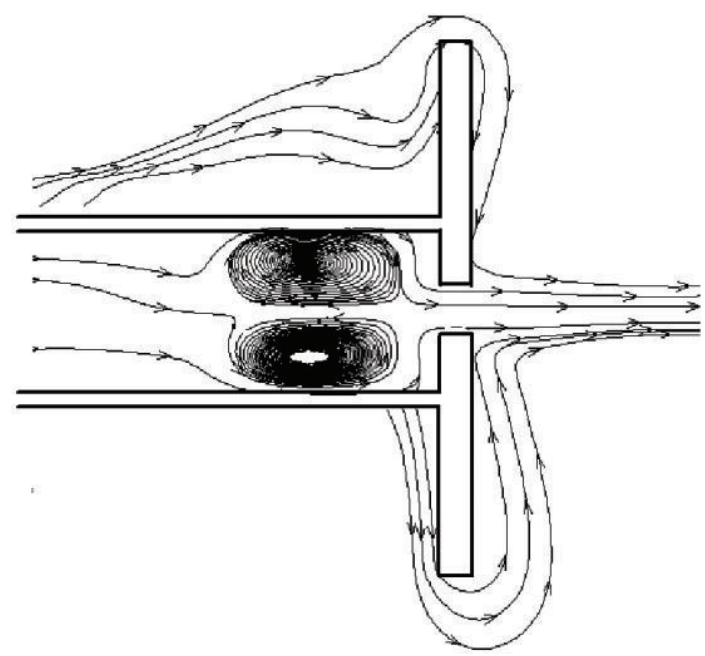

(c) Reynolds stress model

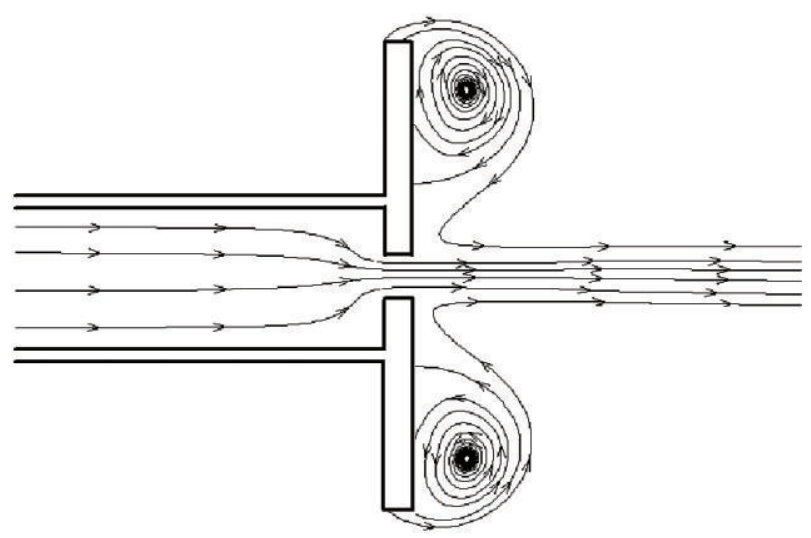

(b) Standard $k$-epsilon model

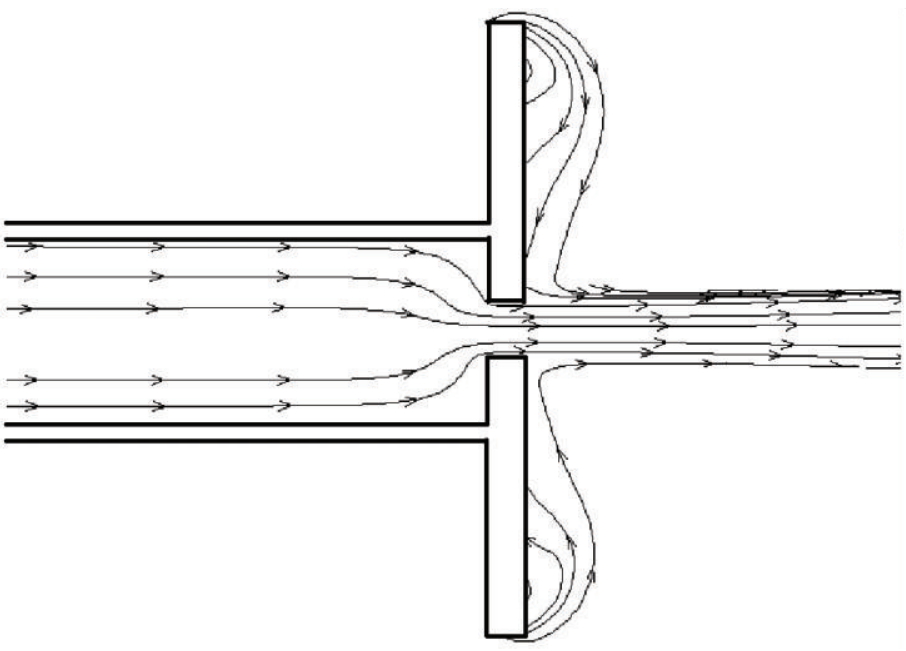

(d) SST $k$-w model

Figure 8: Streamline of cold flow field with different turbulence models.

models (RKE model, SKE model, RSM model, and SST $k-w$ model are included) and four different combustion models (ED model, EDC model, PDF model, and Finite-Rate/ED model) have been compared.

The GRI-MECH 3.0 detailed chemical reaction mechanism, consisting of 325 elementary reactions involving 53 species, was used as the first part of the mechanism and describes the reaction chemistry of $\mathrm{CH}_{4}$. The second part of the mechanism was taken from [30] and involved the reactions of $\mathrm{C} 2-\mathrm{C} 4$ hydrocarbon fuels considered herein. The reaction rates that appear as source terms in the species transport equations are computed based on Arrhenius rate expressions.

Figure 8 shows the different streamline of cold flow field near disk stabilizer using different turbulence models when fuel air mixture velocity is $24 \mathrm{~m} / \mathrm{s}$ and coflowing air velocity is $4.8 \mathrm{~m} / \mathrm{s}$. As is well-known, there are vortexes in the downstream of bluff body (disk in this geometry), so RSM model and model are improper. Roquemore et al. [31] found the coaxial air that converges toward the centerline downstream of the bluff body can form a wake region, which extends approximately one bluff body diameter downstream the stabilizer edge. A toroidal recirculating flow region is formed within the wake region by the interaction of the outer coaxial air with the central-jet flow. The streamline of cold flow field with RKE model accords with Roquemore's research conclusions. So RKE model is the best choice in numerical simulation of bluff body burner.

The generalized finite-rate chemistry formulation is suitable for a wide range of applications including laminar or turbulent reaction systems, and combustion systems with premixed, nonpremixed, or partially premixed flames [28]. Figure 9 shows the profile of temperature in the middle axis with different combustion models. More specifically, combustion models in numerical simulation bluff body burner include probability density function model (PDF), eddy-dissipation model (ED), eddy-dissipation concept model (EDC), and finite-rate/eddy-dissipation model (Finite-Rate/ED). From the figure we can conclude that Finite-Rate/ED model can fit the data of reference suitably.

As shown above, it can be concluded that RKE turbulence model and Finite-Rate/ED combustion model are the best choice in numerical simulation of bluff body burner in this paper. 


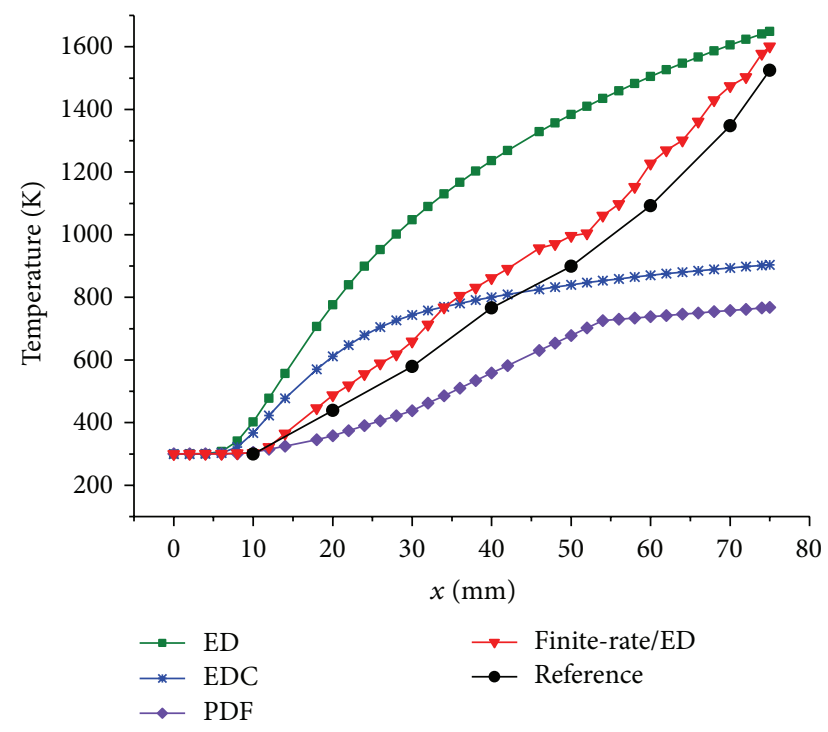

Figure 9: Profile of temperature in the middle axis with different combustion models.

\section{Feature-Parameter-Criterion}

4.1. Feature-Section and Feature-Parameter. In combustors, vortex breakdown of the swirling flow and cross-section extension at the outlet of nozzle will lead to formation of central recirculation zones (CRZ). CRZ is a simply connected zone which is composed of some surfaces whose feature is axial velocity $u=0$. These zones transfer hot combustion products back to the nozzle, which enhances the ignition of unburned gas and thereby stabilizes the flame. With the reduction of inlet fuel air ratio, combustion efficiency and average temperature of flow field will decrease accordingly. Unburned gas flows into CRZ, which causes the average temperature of CRZ to decrease further, meanwhile the sparking distance will increase. When this distance exceeds the region of CRZ, fresh mixed gas could not be heated up by high-temperature gas of CRZ and overmuch fresh mixed gas (temperature is not high enough) flows into CRZ. It induces average temperature of CRZ decrease fast and lean blowout appears.

So the temperature change of CRZ seems to be the best standard of blowout. But in practical process, blowout in primary zone happens earlier than CRZ and the region of temperature decreasing of CRZ is little. It costs too much time if monitor the temperature changes of CRZ. And the prediction accuracy is unacceptable. Moreover, CRZ cannot stand for the changing regularity of whole combustor. To solve the above problems, a surface named Feature-Section which is tangent to the CRZ has been defined in this paper. It has been shown in Figure 10. Of course, under different fuel air ratio, the position and length of CRZ may change, so the position of Feature-Section may also change at the same time. The advantages of Feature-Section are, as next to the CRZ, it can reflect changing regularity of parameters in CRZ downstream sensitively; at the same time, it can monitor more area than CRZ, so it can stand for the combustion characteristic of whole combustor objectively.

To describe the relationship between the change rate of average temperature and change rate of fuel air ratio, a new variable named feature-parameter $\Gamma$ is defined as follows:

$$
\Gamma=\frac{\left|\left(T_{n+1}-T_{n}\right) / T_{n}\right|}{\left|\left(\varphi_{n+1}-\varphi_{n}\right) / \varphi_{n}\right|}
$$

With the change of fuel flow and average temperature, feature-parameter $\Gamma$ will also change. The more intensely the average temperature of feature section $(T)$ changes, the more greatly $\Gamma$ varies. Among them, subscript $n+1$ represents current value and $n$ represents previous value. And $T$ represents average temperature in feature section.

With the decrease of fuel air ratio, average temperature of feature-section will also lower. But this change keeps small at the time of stable combustion, so the feature-parameter $\Gamma$ will remain unchanged. As is well-known, blowout will occur suddenly and there is an obvious change on average temperature of feature-section. Thus, there should be an inflection point on the curves of average temperature and feature-parameter. As Figure 11 has shown, point A and point $\mathrm{B}$ are the inflection points which correspond to the lean blowout fuel air ratio.

4.2. Prediction Process. Numerical prediction of LBO is consistent with actual lean blowout process. Firstly, to numerically calculate two-phase combustion flow field which is far away from lean blowout points and obtain fuel air ratio $\varphi_{0}$ and the average temperature $T_{0}$. Then to reduce fuel air ratio to $\varphi_{1}$, recalculate two phase combustion flow field, and obtain the relevant average temperature $T_{1}$. And obtain the featureparameter $\Gamma$ by using formula (11). To repeat this calculation till $\varphi_{n+1}$. If $\Gamma_{n+1}>5, \varphi_{n+1}$ will be affirmed as fuel air ratio of lean blowout. If $\Gamma_{n+1} \leq 5$, take $\varphi_{n+1}$ as $\varphi_{n}$, reduce fuel air ratio and make the recalculation. The prediction process is shown as Figure 12.

\section{Results and Analysis}

5.1. Lean Blowout of Annular Combustor of Gas Turbine. Lean blowout process, "M" flame, and some effect factors on lean blowout of combustor of gas turbine have been discussed in this paper.

5.1.1. Blowout Process of Annular Combustor and "M" Flame. Table 3 shows the results of LBO limit for an annular model combustor by using Feature-Parameter-Criterion. It shows that the $\mathrm{LBO}$ in this condition is 0.00415 . The error of this result is $4.48 \%$ with experimental data.

Figure 13 shows the experiment [32] and simulation images of blowout process. The analysis of the images indicates that (a) the prediction of lean blowout process with FPC is in agreement with corresponding experimental image, and (b) there is an obvious portent before lean blowout- " $M$ " flame. 

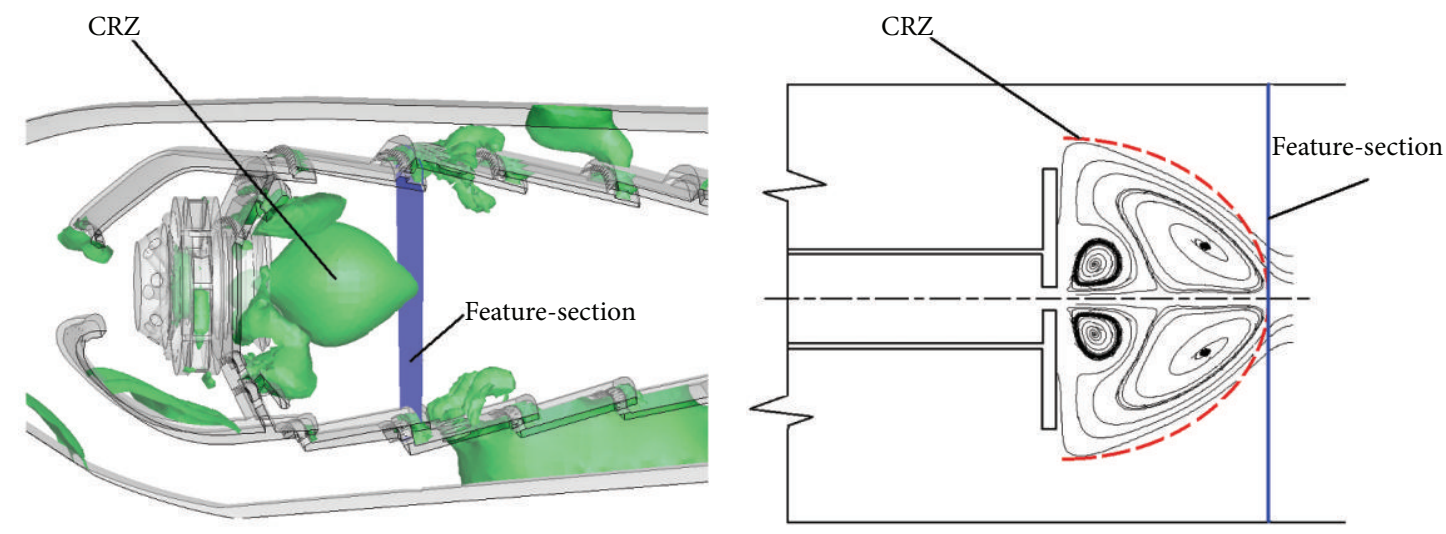

FIGURE 10: Schematic diagram of feature-section and CRZ.

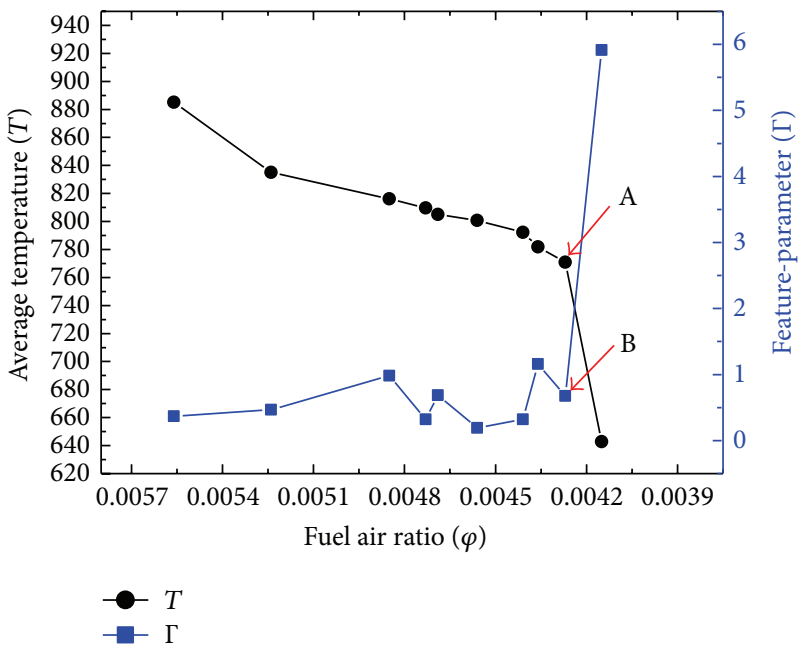

FIGURE 11: Changes of average temperature, feature-parameter, and fuel air ratio in a typical lean blowout course.

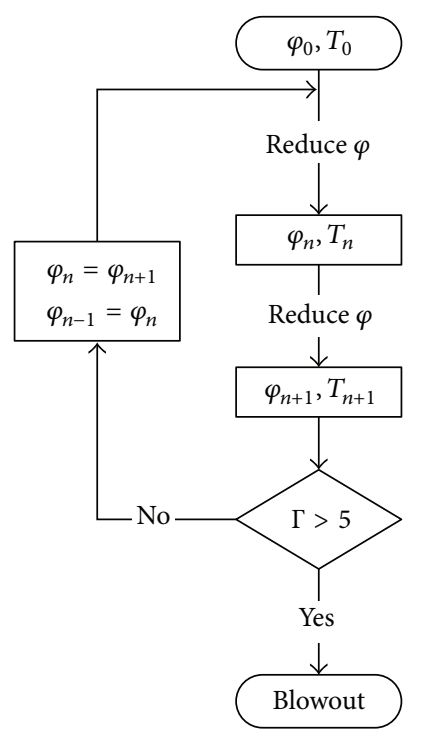

Figure 12: Prediction process of Feature-Parameter-Criterion.
TABLE 3: Prediction of LBO limit for gas turbine annular combustor.

\begin{tabular}{lcccc}
\hline & $\varphi$ & $T$ & $\Delta \varphi$ & $\Gamma$ \\
\hline 0 & 0.0187 & 1050.745 & - & - \\
1 & 0.0125 & 996.971 & 0.3316 & 0.154 \\
2 & 0.0098 & 974.352 & 0.216 & 0.105 \\
$n-1$ & 0.00436 & 781.842 & 0.0113 & 1.1593 \\
$n$ & 0.00427 & 770.964 & 0.0206 & 0.0674 \\
$n+1$ & 0.00415 & 642.851 & 0.0281 & 5.913 \\
\hline
\end{tabular}

The formation reasons for " $\mathrm{M}$ " flame are as follows.

(a) Because of central recirculation zone, there appears high negative velocity on the center of the axial line. When fuel air ratio is low, the back-flowed lowtemperature air will flow into the center and compel the central to become short. Thus, "M" flame appears.

(b) A hollow and conical shape presents for the oil droplet (As shown in Figure 14), which makes more fuel going into the central area and less fuel going to the axial line of the flame tube. Thus, under the blowout conditions, the sufficient combustion cannot be ensured, which causes "M" flame. The distribution of oil droplet is shown intuitively in Figure 14.

Figure 15 shows the changes of flame front when fuel air ratio of annular combustor decreases gradually. In this process, with the decrease of the temperature of primary zone, flame front (contours of $2000 \mathrm{~K}$ is used as a symbol) changes into " $M$ " shape gradually. Because of this " $M$ " flame, the decrease speed rate of temperature in central point is more than that in other points of flame front. So it also induces the process of collapsing of flame and lean blowout.

Figure 16 shows the contours of three typical temperature distribution when lean blowout occurs.

(a) There is an obvious portent before lean blowout appears, " $\mathrm{M}$ " flame shape. The temperature of this primary flame is $2600 \mathrm{~K}$. It means even though combustor works under lean blowout conditions, there is also high-temperature zone on the center of 

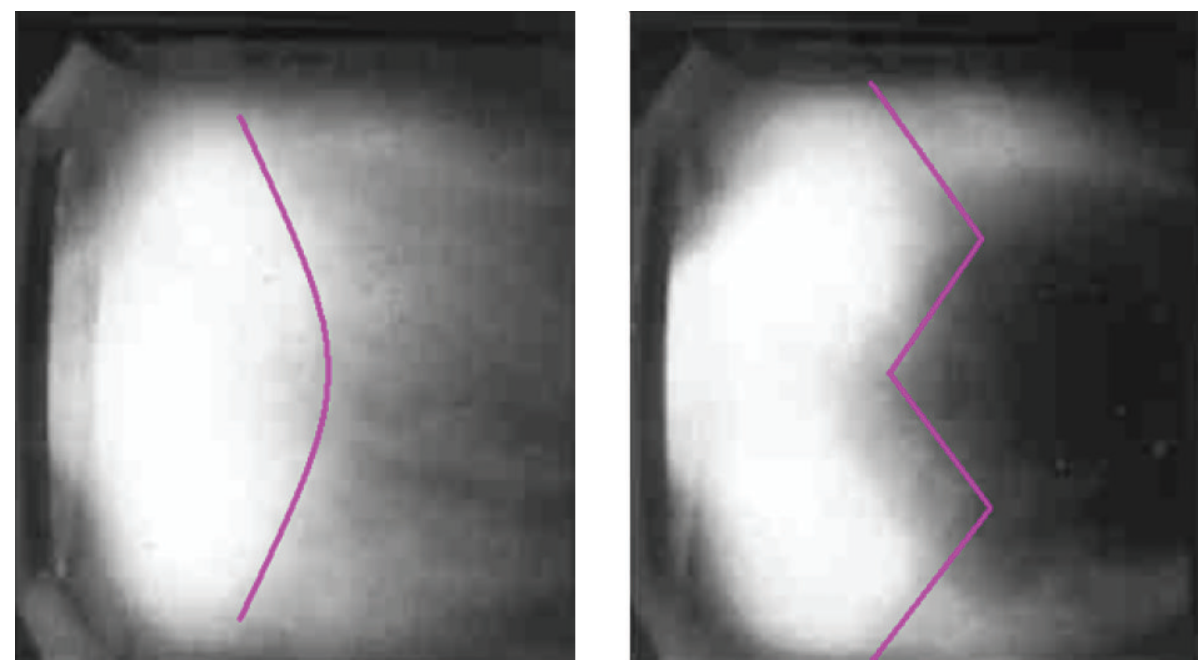

(a)
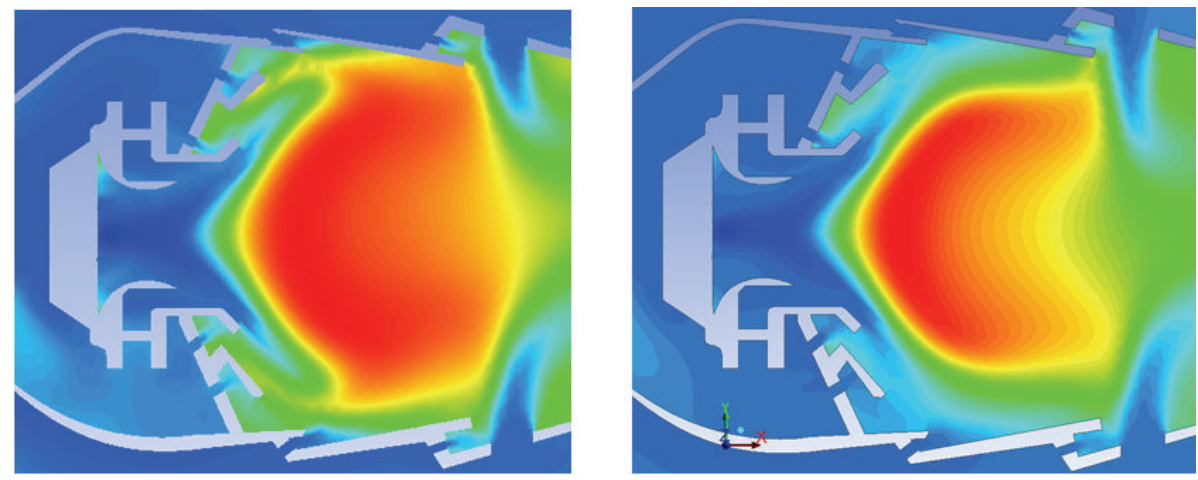

(b)

FIGURE 13: Experiment and simulation images of blowout process.
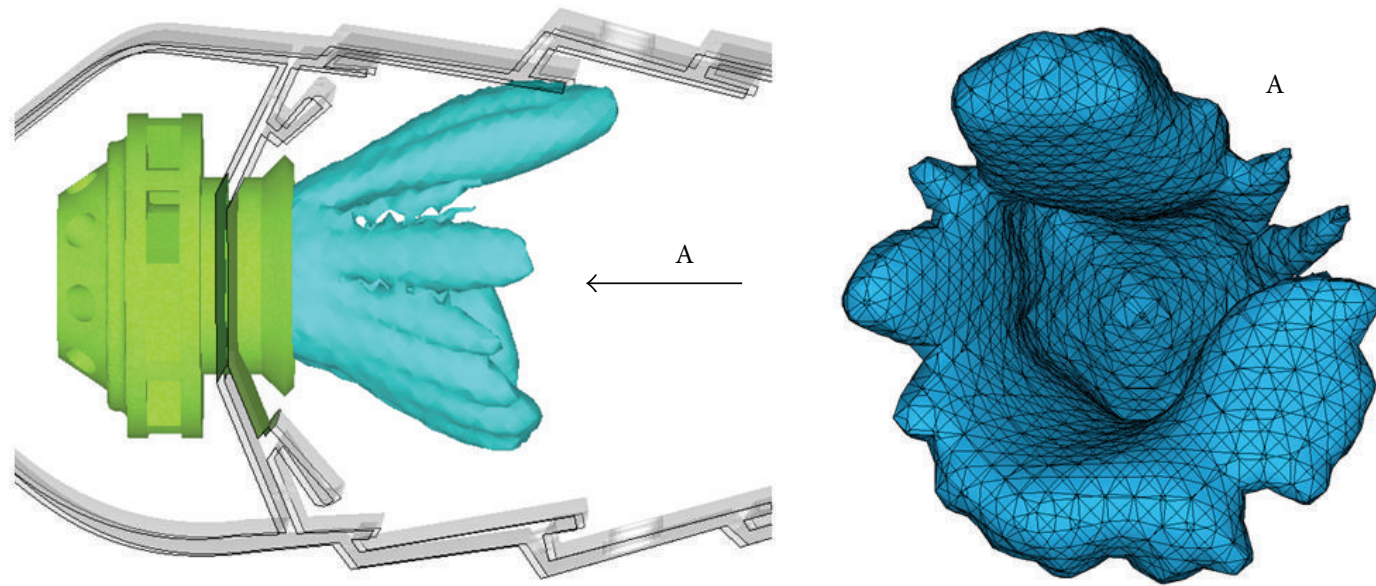

Figure 14: Distribution of oil droplet.

combustor. But the area of this zone is small, the diameter is quarter of flame tube.

(b) The previous experiment proves that there is no obvious flame boundary outside the primary flame front, but there exists a zone filled with high-temperature mixing gas which is shown in Figure 15, the zone equal-temperature is indicated by $2200 \mathrm{~K}$.

(c) Some cold air with temperature of $1300 \mathrm{~K}$ insulates the high-temperature zone and flame tube. It protects the metal wall and extends the life of the flame tube. 


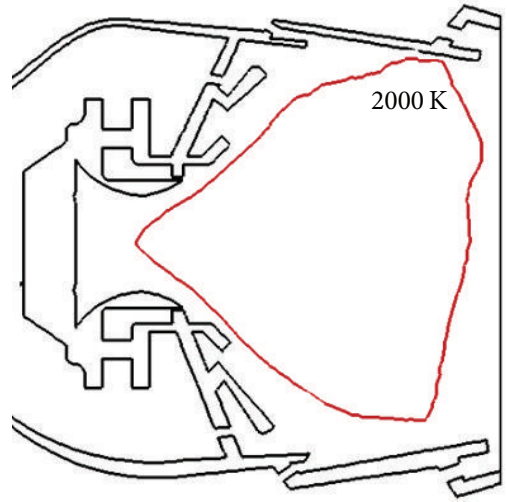

(a) $\varphi=0.0187$

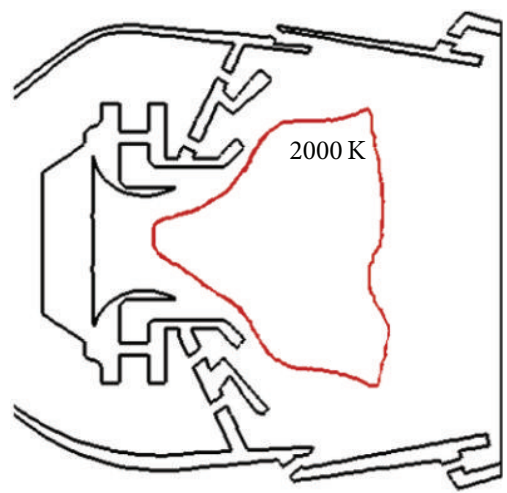

(d) $\varphi=0.00574$

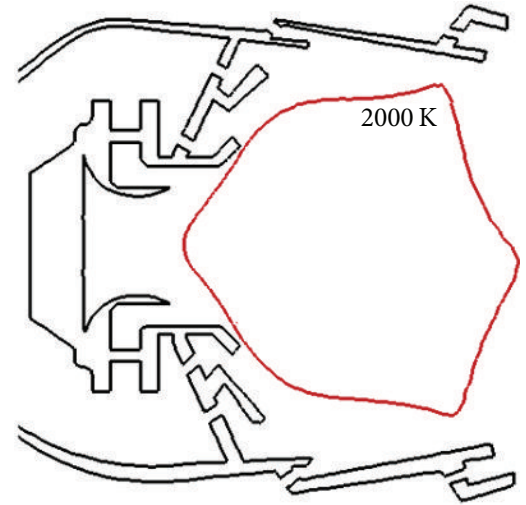

(b) $\varphi=0.0098$

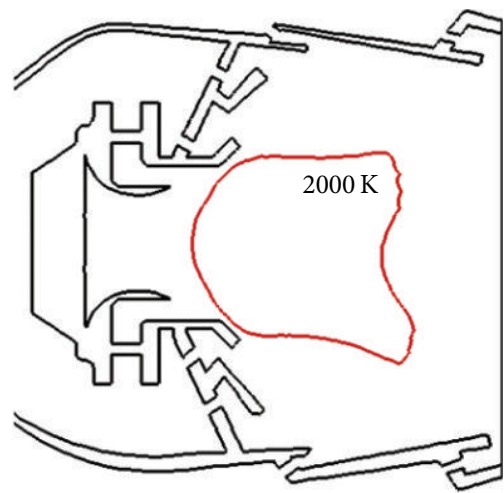

(e) $\varphi=0.00473$

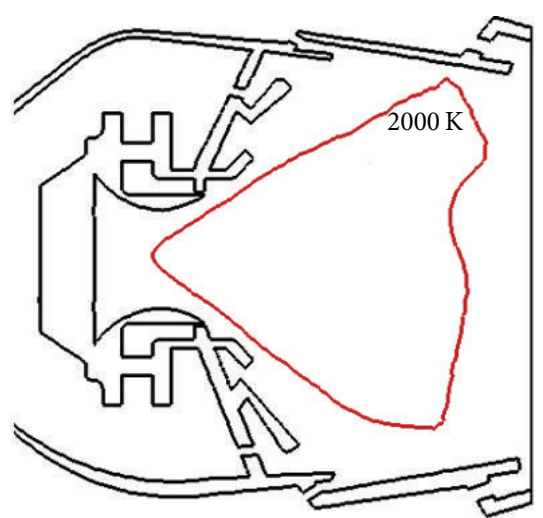

(c) $\varphi=0.00785$

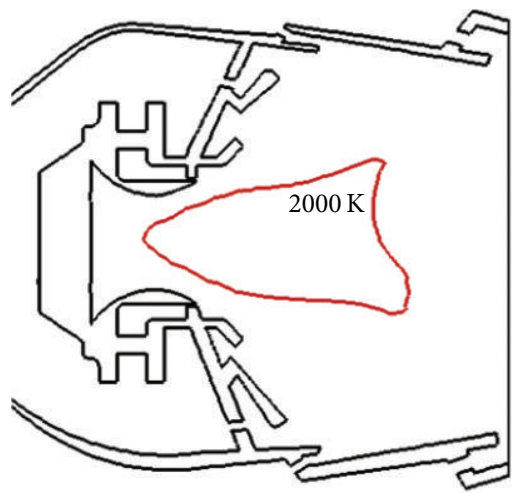

(f) $\varphi=0.00415$

FIGURE 15: Changes of flame front with decreasing of fuel air ratio.

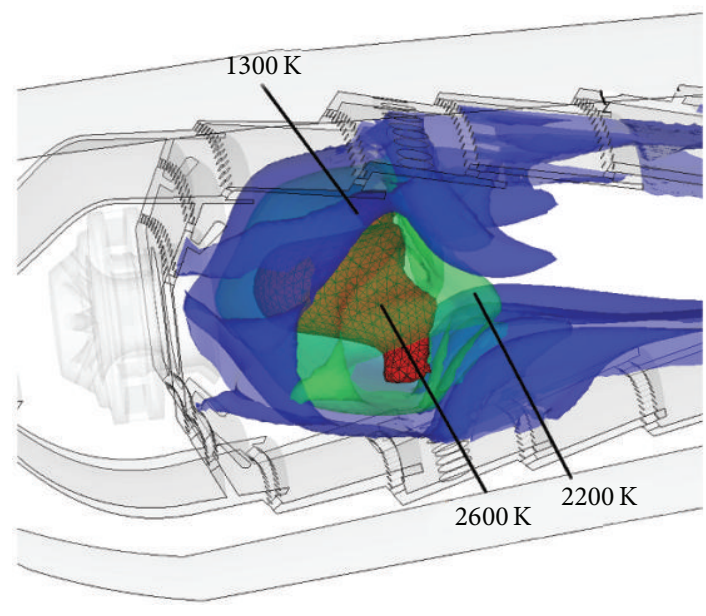

FIGURE 16: Contours of three typical temperatures.

5.1.2. Factors in Lean Blowout of Gas Turbine Combustor. Numerical prediction of LBO under different flow velocity of the inlet and different temperature of air has been done in this paper by using Feature-Parameter-Criterion. The prediction results are compared with experimental data [33] for testing and verifying the accuracy of this new method. The results are shown in Figures 17 and 18.

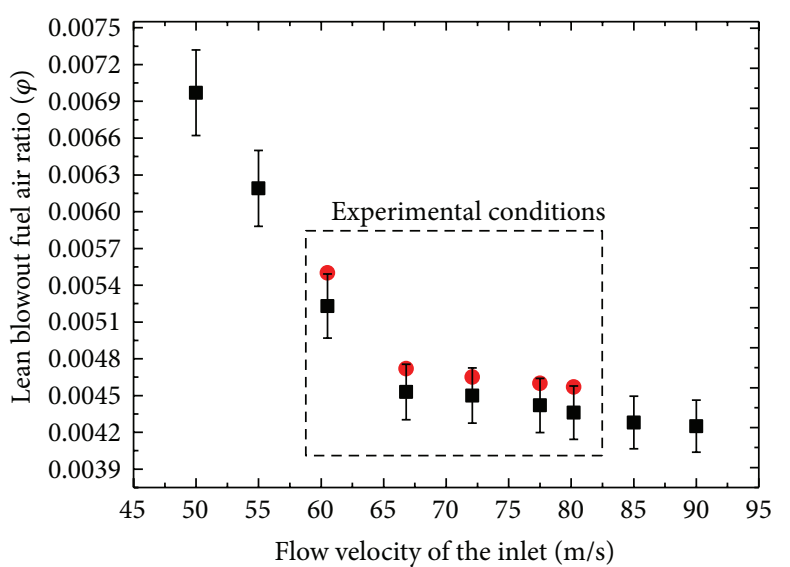

- Prediction results

- Experimental data

FIGURE 17: Effect of flow velocity of the inlet on lean blowout fuel air ratio.

Figure 17 shows the effects of flow velocity on LBO limit. It shows that lean blowout fuel air ratio will decline gradually as flow velocity is increased. The reason is that high-velocity air will disperse oil droplet into large space, and which will benefit the mixture between air and fuel. So the lean blowout 

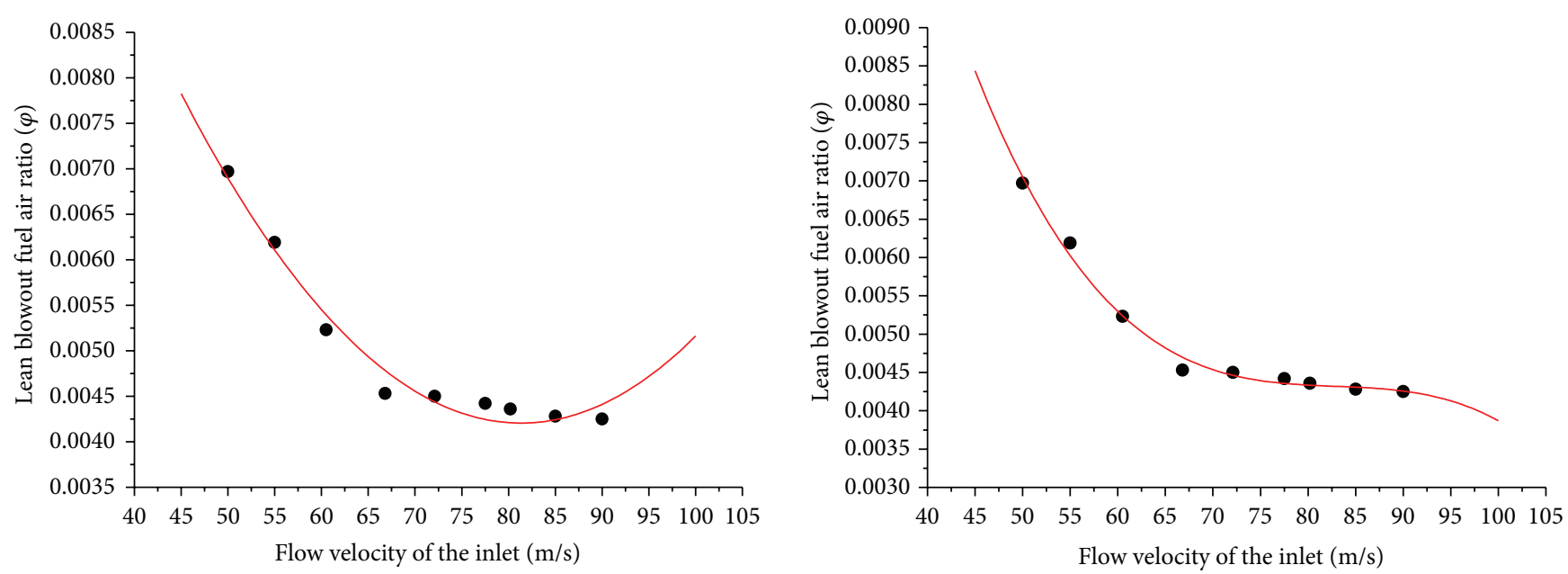

- Numerical results Fitting curve 1

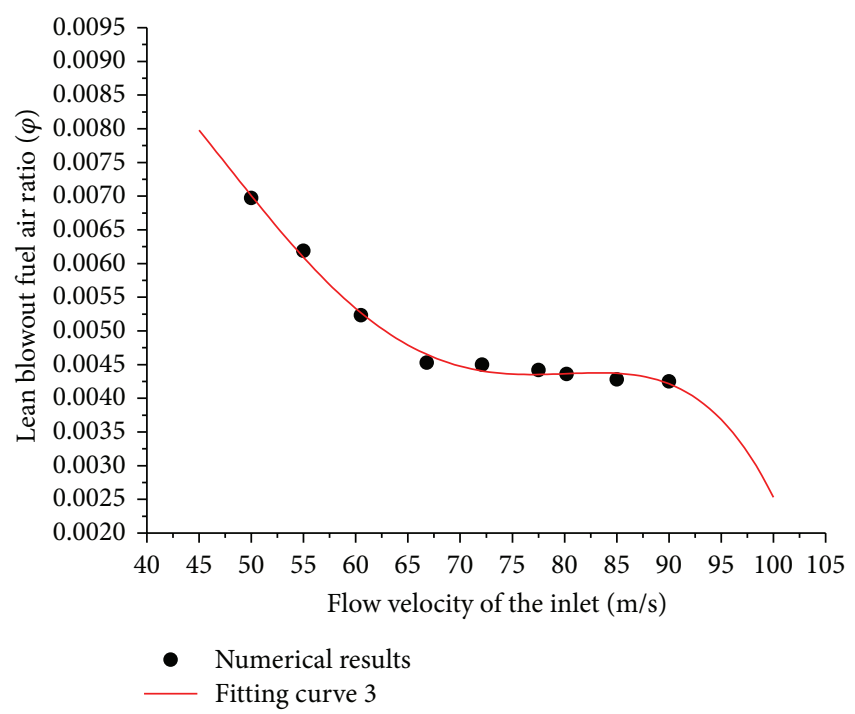

- Numerical results Fitting curve 2

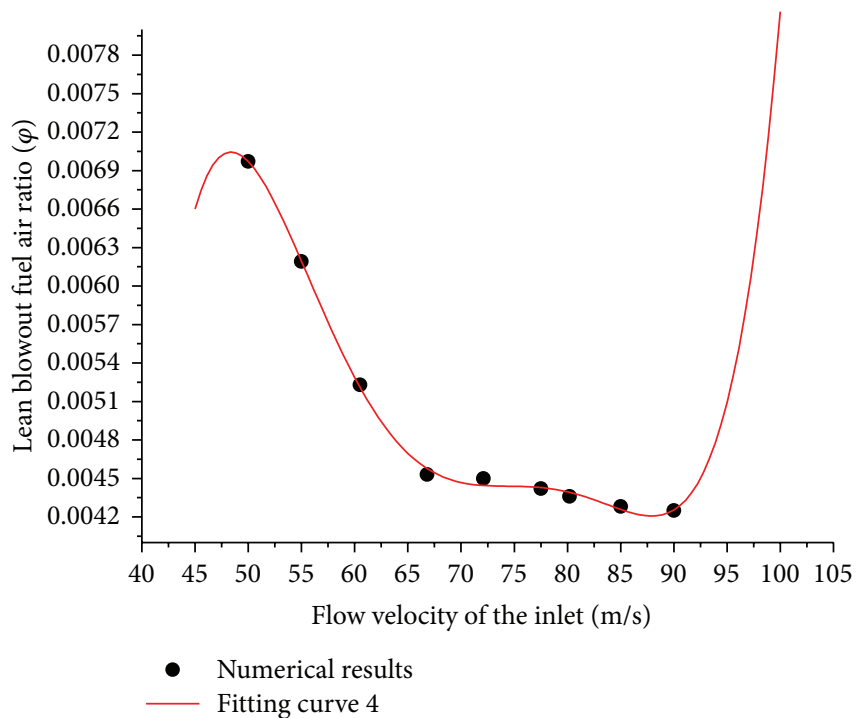

Figure 18: Curves of lean blowout fuel air ratio versus of flow velocity of the inlet and fitting curve.

fuel air ratio decreases. The max error between experimental data and prediction results is $5.01 \%$, it can be accepted.

For describing above relationship between flow velocity of the inlet $(V)$ and lean blowout fuel air ratio $(\varphi)$, fitting formula of polynomials function could be assumed as follows:

$$
\begin{aligned}
\varphi= & a \times V^{5}+b \times V^{4}+c \times V^{3} \\
& +d \times V^{2}+e \times V+f .
\end{aligned}
$$

Fitting of the numerical data results by Least Square Method, the value of $a, b, c, d, e, f$ can be gained as shown in Table 4. Figure 18 shows the numerical results, and the different fitting curve originated from fitting formula. It can be concluded that the error and trend of curve of cubic polynomial is the best. And the final function which describe $\varphi$ and $V$ is shown below:

$$
\begin{aligned}
\varphi_{3}= & -2.97 \times 10^{-9} V^{4}+7.6 \times 10^{-7} V^{3} \\
& -6.83 \times 10^{-5} V^{2}+0.00242 V-0.0197 .
\end{aligned}
$$

Figure 19 shows the effects of air temperature on LBO limit. It shows that when air temperature is less than $397 \mathrm{~K}$, lean blowout fuel air ratio declines gradually as air temperature is increased. The reason is (a) high-temperature air makes the well effect of oil droplet evaporation. The well mixture of air and fuel makes the well performance of combustor and makes the lower lean blowout fuel air ratio. (b) With the increasing of air temperature, heat requirement of CRZ decreases and most of energy can be used to keep stable combustion of primary combustion zone. So the combustor will not blowout quickly. 
TABLE 4: Value of constant about lean blowout fuel air ratio and flow velocity of the inlet.

\begin{tabular}{ccccccc}
\hline & $a$ & $b$ & $c$ & $d$ & $f$ \\
\hline$\varphi_{1}$ & 0 & 0 & 0 & $-7.24 \times 10^{-8}$ & $1.8 \times 10^{-5}$ & $-4.46 \times 10^{-4}$ \\
$\varphi_{2}$ & 0 & 0 & $7.6 \times 10^{-7}$ & $-6.83 \times 10^{-5}$ & -0.0015 & 0.02235 \\
$\varphi_{3}$ & 0 & $-2.97 \times 10^{-9}$ & $-1.66 \times 10^{-7}$ & $2.34 \times 10^{-5}$ & -0.00162 & 0.04592 \\
$\varphi_{4}$ & $4.67 \times 10^{-10}$ & -1.6242 & 0.0549 & -0.0197 \\
\hline
\end{tabular}

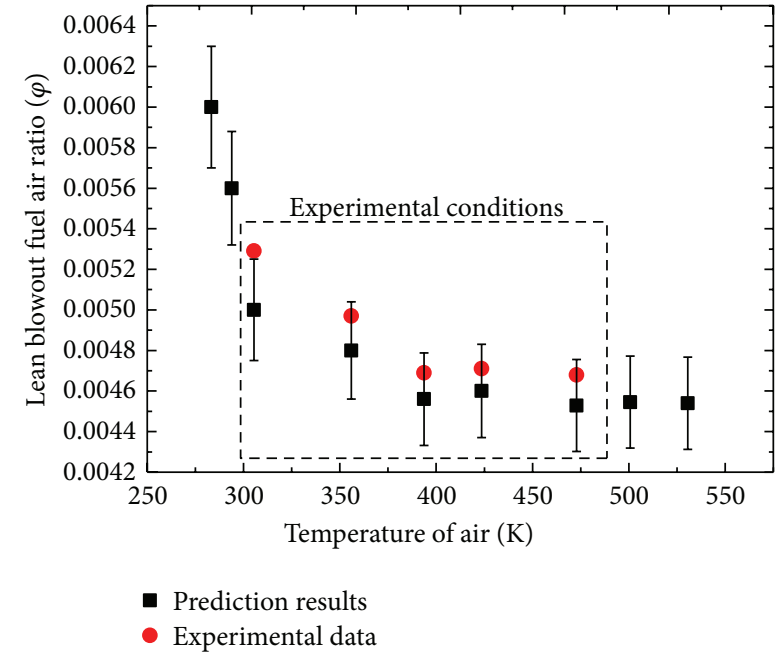

FIGURE 19: Effect of air temperature on lean blowout fuel air ratio.

But if air temperature is over the critical point ( $397 \mathrm{~K})$, oil droplets which are in primary zone evaporate completely in a short time with the action of high-temperature air. Even raise the air temperature, it does not promote the mixing of fuel and air. So LBO fuel air ratio does not change as air temperature is increasing. If air temperature is less than $300 \mathrm{~K}$, lean blowout fuel air ratio is over 0.0055 , it is inadmissible by gas turbine combustor.

Figure 20 shows the relationship between droplet averaged-diameter (ds) and lean blowout fuel air ratio in different initial flow temperature.

When initial flow temperature is $423 \mathrm{~K}$, the analysis of the figure indicates that with the increasing of droplet averageddiameter, lean blowout fuel air ratio undergoes three different processes.

(a) When $\mathrm{ds}<70 \mu \mathrm{m}$, LBO fuel air ratio almost remains unchanged as droplet averaged-diameter is increased. The reason is that droplet averaged-diameter is small and the droplet life is short. Most of the droplets evaporate quickly and could only arrive at the edge of central recirculation zone. So air and fuel can mix witheachother well and LBO fuel air ratio remains unchanged.

(b) When $70 \mu \mathrm{m}<\mathrm{ds}<90 \mu \mathrm{m}$ (point $\mathrm{C}$ is a turningpoint), LBO fuel air ratio declines quickly as droplet averaged-diameter is increased and reaches to the minimum value at $90 \mu \mathrm{m}$ (point D). The reason is with the increasing of droplet averaged-diameter,

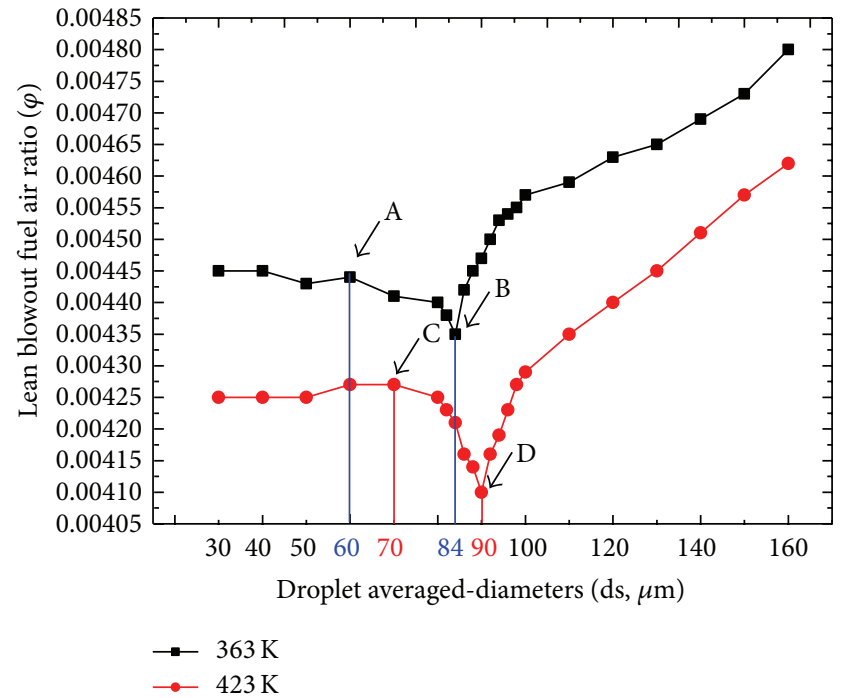

FIGURE 20: Effects of fuel droplet averaged-diameters on lean blowout fuel air ratio in different initial flow temperature.

some large-sized droplets arrive at the center of CRZ and burn there. As the flame presents " $M$ " shape, temperature in the center line decreases slowest and they can transport energy to other zones of the combustor. So LBO fuel air ratio declines.

(c) When $\mathrm{ds}>90 \mu \mathrm{m}$, LBO fuel air ratio rises quickly as droplet averaged-diameter is increased. Because at this time, droplets averaged-diameter increases further and large-sized droplets cannot evaporate completely at CRZ. With the effect of inertia force, some large-sized droplets go through CRZ and arrive at the edge of primary combustion zone. These droplets take away the energy of CRZ and make the temperature of CRZ decrease. It induces the lean blowout phenomenon and makes LBO fuel air ratio rise quickly.

To explain the above phenomenon and reasons intuitively, distribution of oil droplet at different averageddiameters is shown in Figure 21. When ds $=50 \mu \mathrm{m}$, droplets only distribute in front of combustor (almost at the edge of CRZ). When $\mathrm{ds}=90 \mu \mathrm{m}$, some droplets do not evaporate and arrive at the center of CRZ. When $\mathrm{ds}=150 \mu \mathrm{m}$, most of droplets go through CRZ and arrive at the edge of primary combustion zone. The distribution of oil droplet affects the temperature of combustor and induces the different changes of lean blowout limit. 


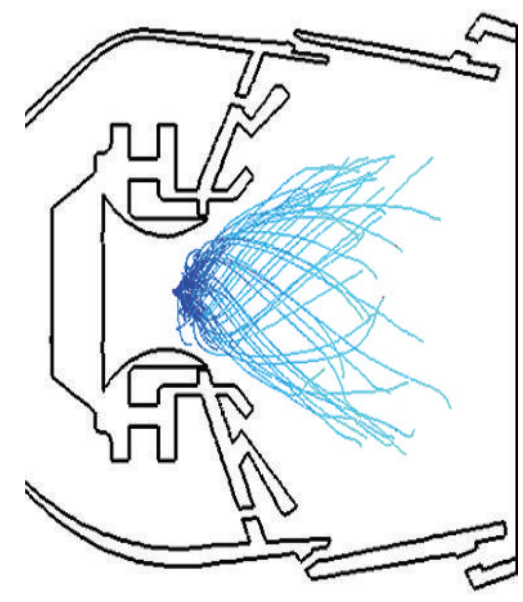

(a) $\mathrm{ds}=50 \mu \mathrm{m}$

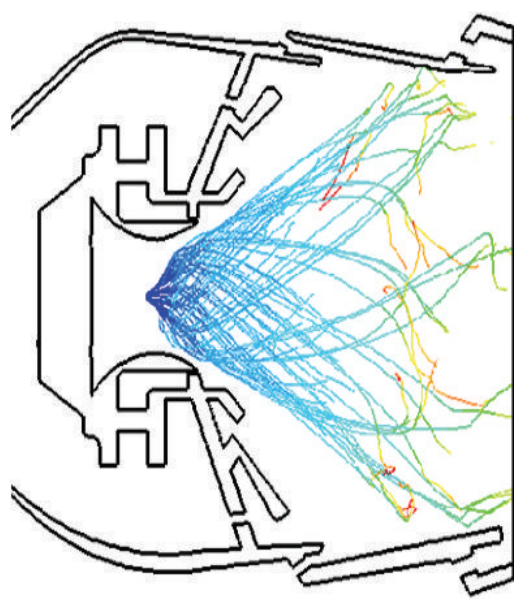

(b) $\mathrm{ds}=90 \mu \mathrm{m}$

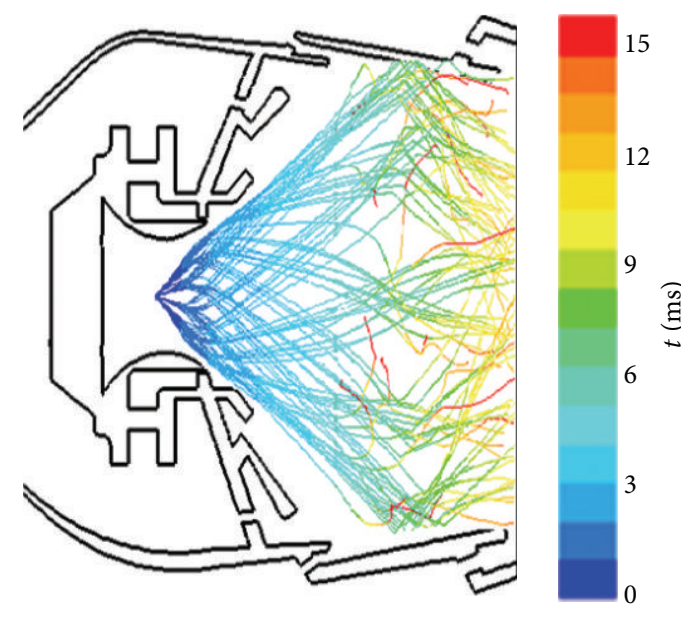

(c) $\mathrm{ds}=150 \mu \mathrm{m}$

FIGURE 21: Distribution of droplet at different averaged-diameters.

As the evaporation rate of droplets also is affected by turbulent mixing and flow temperature, so some comparison has been done in this paper. When initial flow temperature is $363 \mathrm{~K}$, the basic trend of curve is the same. But when initial flow temperature is lower, turning-points are $60 \mu \mathrm{m}$ and $84 \mu \mathrm{m}$ (point $\mathrm{A}$ and point $\mathrm{B}$ are the turning-points). They are smaller than the high-temperature results. The reason is that lower initial flow temperature cannot make fuel droplet evaporation in a short time, so some large-sized droplets arrive at the center of CRZ and they can transport energy to other zones of the combustor. It is benefiting the combustion stability. So LBO fuel air ratio declines quicker than higher initial flow temperature.

The effects of flow distribution between swirlers and primary holes have been researched in this paper. Then comparison between simulated results and experimental data has been shown.

Table 5 shows a detailed scheme of this research.

"Half" and "Full" in Table 5 mean the difference of airflow volume through homologous parts. For example, Figure 22 shows the sketch of decrease of air into primary holes [34]. For different scheme, pressure of outlet and total flow of combustor are not the same. In this paper, average value method has been used to eliminate the influence of these differences. Specifically, in the experiment, the researchers test 3 times for each scheme and show the average value for revising the error.

All the final results of different schemes are shown in Figure 23. It shows that

(a) Reducing airflow volume through swirlers will extend stabilized combustion region. And the influence of oblique-hole is more than swirl-vane on lean blowout. The reason is when combustor works near blowout condition, the volume of flame is small; air for droplet atomization and combustion mainly comes from oblique-hole which is near the nozzle. So the changes of airflow volume through oblique-hole will affect blowout directly.
TABLE 5: Experimental and simulated scheme.

\begin{tabular}{llcc}
\hline Scheme number Oblique-hole swirler & Swirl-vane & Primary holes \\
\hline 1 & Half & Half & \\
2 & Full & Half & Half \\
3 & Half & Full & \\
4 & Full & Full & \\
\hline 5 & Full & Full & \\
6 & Half & Full & Full \\
7 & Half & Half & \\
\hline
\end{tabular}

(b) Lean blowout fuel air ratio will improve by decreasing airflow volume through primary holes and it is bad for the stabilized combustion performance.

(c) The max error (structure 7) between experiment and simulation is $5.43 \%$. It shows that the predictions of Feature-Parameter-Criterion are in agreement with corresponding experimental dates.

5.2. Lean Blowout of Bluff Body Burner. Lean blowout process and some factors in lean blowout of bluff body burner have been discussed in this part.

5.2.1. Blowout Process of Bluff Body Burner. Table 6 shows the results of LBO limit for bluff body burner by using FeatureParameter-Criterion (fuel air mixture velocity is $23.8 \mathrm{~m} / \mathrm{s}$ and coflowing air velocity is $4.8 \mathrm{~m} / \mathrm{s}$ ). It shows that the LBO limit in this condition is 0.00854 . The experiment value is 0.00817 and the error is $4.51 \%$.

Figure 24 shows the experiment [28] and simulation images of blowout process about bluff body burner. The flame is originally slender and relatively long. When the fuel air mixture is relatively low $(24 \mathrm{~m} / \mathrm{s})$, flame ignition begins at a short quenching distance downstream from the disk and a lengthy rich flame is observed. If this velocity increases and exceeds $30 \mathrm{~m} / \mathrm{s}$, the flame became shorter and the boundary 


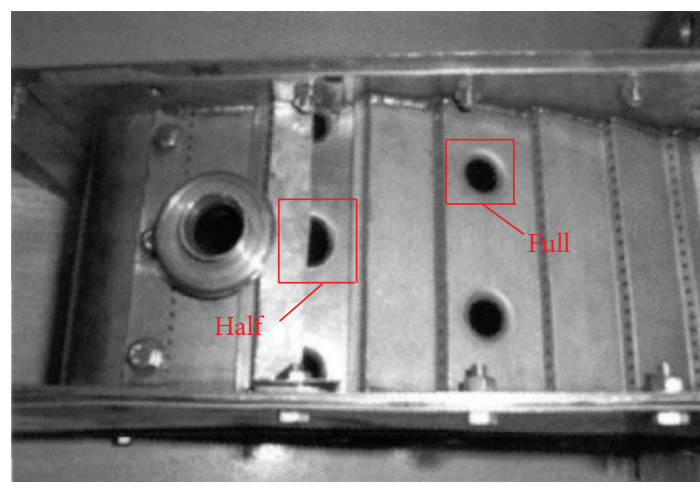

FIGURE 22: Sketch of decrease of air into primary holes.

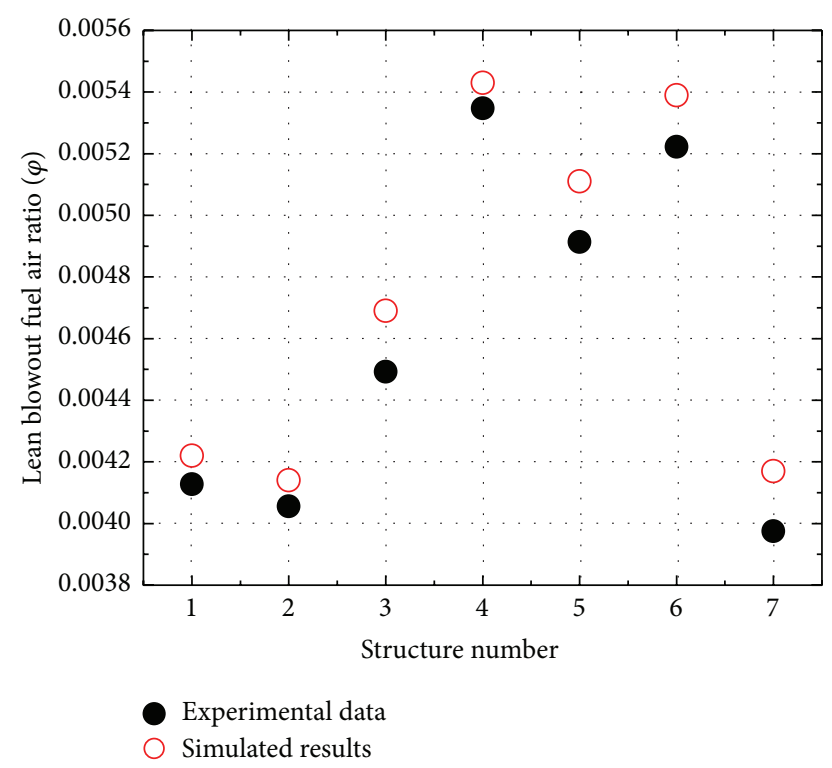

FIGURE 23: Experimental data and simulated results of blowout fuel air ratio with different structures.

of high-temperature flame reduces. Further increase velocity would shorten the flame further and concentrate the flame near disk.

5.2.2. Factors in Lean Blowout of Bluff Body Burner. Figure 25 shows the changes of lean blowout fuel air ratio at different fuel air mixture velocities it can conclude that (a) lean blowout fuel air ratio will rise as fuel air mixture velocity is increased. The reason is high velocity of fuel air mixture could destroy vortex near disk and lead to unstable combustion of bluff body burner. So the lean blowout performance worsens and the lean blowout fuel air ratio increases. (b) The error between prediction results with Feature-Parameter-Criterion and experimental data is about $5 \%$ and the accuracy is acceptable.

Five different structures of bluff body burner are shown in Figure 26. In general, there are two kinds of structures: cone and disk. The angles of cone changes from 30 to 90. Figure 27 shows the changes of lean blowout fuel air ratio at
TABLE 6: Prediction of LBO limit for bluff body burner.

\begin{tabular}{lcccc}
\hline & $\varphi$ & $T$ & $\Delta \varphi$ & $\Gamma$ \\
\hline 0 & 0.02554 & 1205 & - & - \\
1 & 0.02409 & 1185 & 0.057 & 0.292 \\
2 & 0.02264 & 1173 & 0.060 & 0.168 \\
$n-1$ & 0.01104 & 1159 & 0.512 & 0.023 \\
$n$ & 0.00979 & 1146 & 0.113 & 0.099 \\
$n+1$ & 0.00854 & 413 & 0.128 & 5.009 \\
\hline
\end{tabular}

different structures. It can conclude that (a) lean blowout fuel air ratio will rise as cone angle is increased. So the smaller angle of cone benefits the stability of combustion. (b) When fuel air mixture velocity is less than $39.7 \mathrm{~m} / \mathrm{s}$, the lean blowout performance of cone 90-degree is almost the same with disk; when this velocity is higher (more than $39.7 \mathrm{~m} / \mathrm{s}$ ), disk is the worst structure for stable combustion.

\section{Conclusion}

A new method named Feature-Parameter-Criterion (FPC) has been put forward in this paper for predicting lean blowout limit. The effects of operation condition (such as flow velocity, air temperature, droplet average-diameter, and flow distribution between swirlers and primary holes) on LBO limit of gas turbine combustor have been researched. Then the influences of fuel air mixture velocity and bluff body structures on bluff body burner's LBO limit have also been analyzed by use of FPC. The results showed that " $M$ " flame could be the portent for predicting lean blowout of gas turbine combustor. The simulation of LBO limit based on FPC is in good agreement with the experiment data (the errors are about 5\%), and this method is reliable for engineering applications. Other conclusions are as follows.

(1) Lean blowout fuel air ratio declines gradually as flow velocity is increased. The fitting formula is $\varphi=$ $-2.97 \times 10^{-9} V^{4}+7.6 \times 10^{-7} V^{3}-6.83 \times 10^{-5} V^{2}+$ $0.00242 V-0.0197$.

(2) As air temperature increases, when air temperature is less than $397 \mathrm{~K}, \mathrm{LBO}$ fuel air ratio declines gradually, and when air temperature is over the critical point $(397 \mathrm{~K})$, lean blowout fuel air ratio remains unchanged.

(3) When initial flow temperature is $423 \mathrm{~K}$, as droplet averaged-diameter is increased, if $\mathrm{ds}<70 \mu \mathrm{m}$, LBO fuel air ratio almost remains unchanged, and if $70 \mu \mathrm{m}<\mathrm{ds}<90 \mu \mathrm{m}$, LBO fuel air ratio decline quickly and reaches to the minimum value at $90 \mu \mathrm{m}$, as well as if $\mathrm{ds}>90 \mu \mathrm{m}, \mathrm{LBO}$ fuel air ratio rise quickly. When initial flow temperature is $363 \mathrm{~K}$, the basic trend of curve is the same. But the value of turning-points is smaller than the high-temperature results.

(4) Reducing airflow volume through swirlers will extend stabilized combustion region. And LBO fuel air ratio 

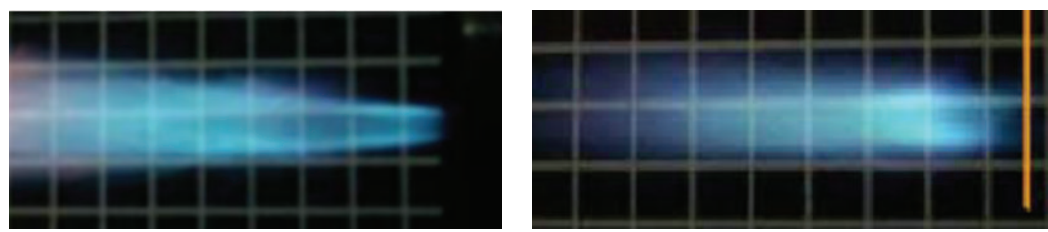

(a)
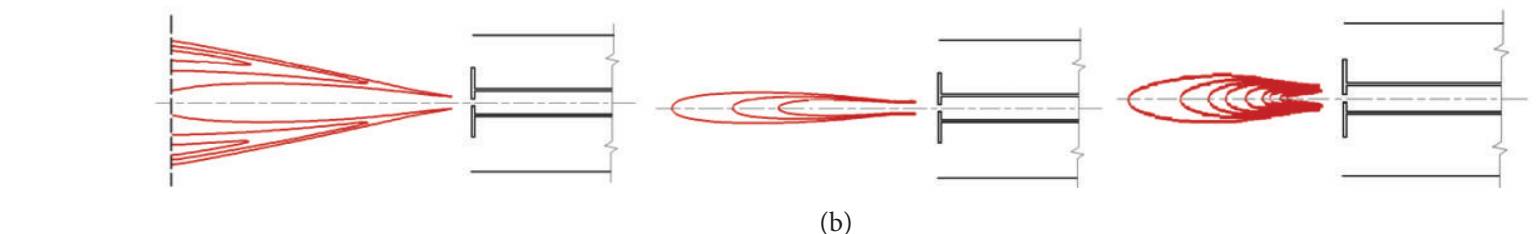

(b)

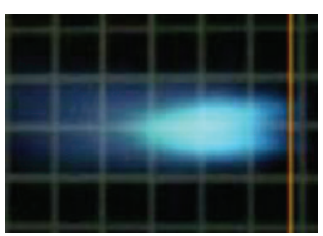

FIGURE 24: Experiment and simulation images of blowout process about bluff body burner.

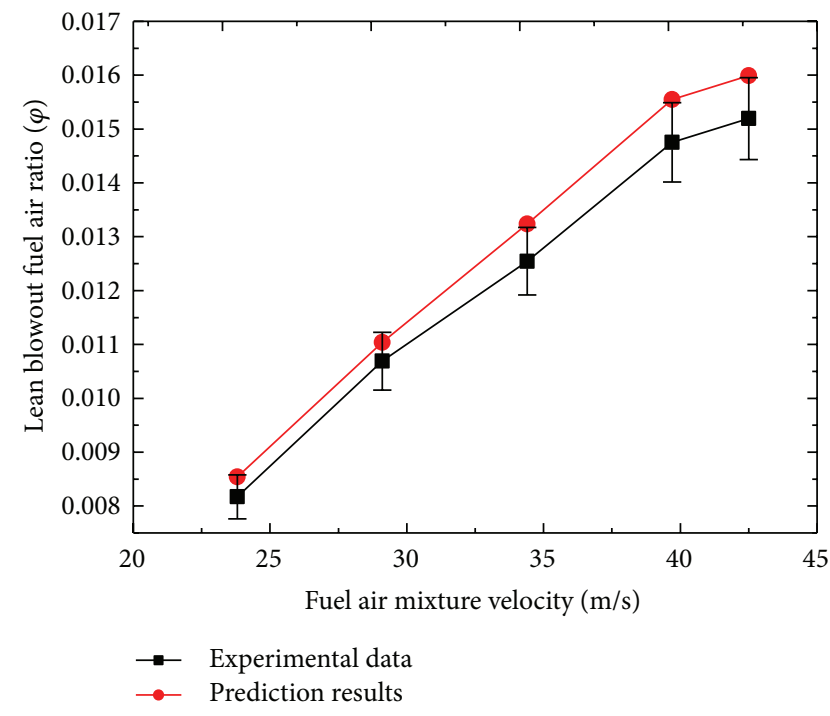

FIGURE 25: Effect of fuel air mixture velocity on lean blowout fuel air ratio.

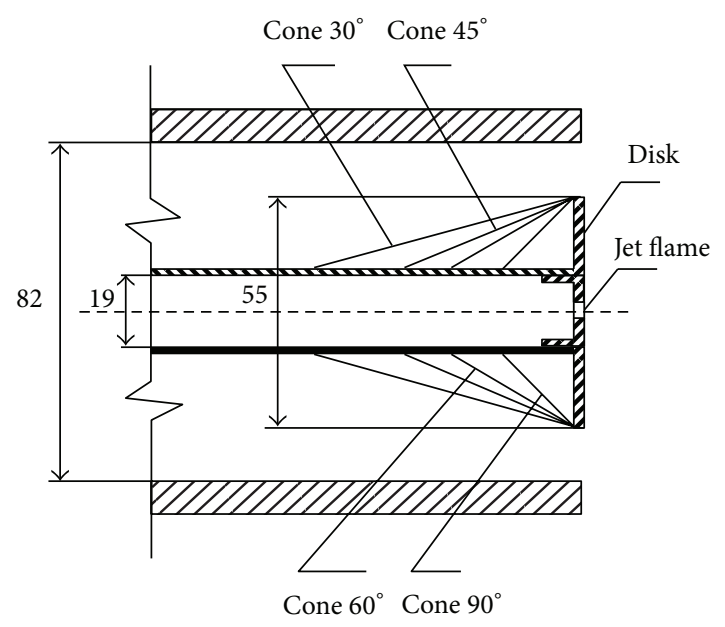

FIGURE 26: Schematic of different structures of bluff body burner.

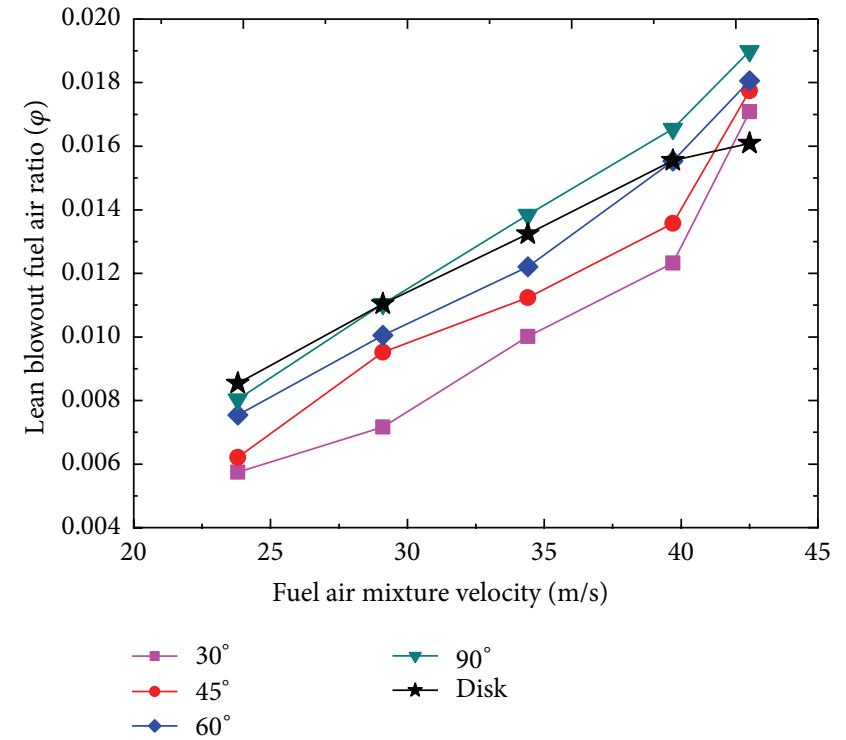

FIGURE 27: Effect of cone angle and disk on lean blowout fuel air ratio.

will improve by decreasing airflow volume through primary holes.

(5) Lean blowout fuel air ratio will rise as fuel air mixture velocity and cone angle are increased.

\section{Nomenclatures}

$\rho: \quad$ Density $\left(\mathrm{kg} \cdot \mathrm{m}^{-3}\right)$

$\bar{V}$ : Velocity $\left(\mathrm{m} \cdot \mathrm{s}^{-1}\right)$

$S_{m}$ : Mass added to the continuous phase from the dispersed second phase and any user-defined sources

$p$ : Static pressure $(\mathrm{Pa})$

$\tau$ : Stress tensor

$\vec{F}$ : External body forces or user-defined sources

$\vec{q}:$ Radiation heat flux $\left(\mathrm{J} \cdot \mathrm{m}^{-2} \cdot \mathrm{s}^{-1}\right)$ 
$R_{i}$ : Net rate of production of species $i$ by chemical reaction

$Q_{i}$ : Rate of creation by addition from the dispersed phase plus any user-defined sources

$k$ : Turbulent kinetic energy $\left(\mathrm{m}^{2} \cdot \mathrm{s}^{-2}\right)$

$\varepsilon$ : Kinetic energy dissipation rate $\left(\mathrm{m}^{2} \cdot \mathrm{s}^{-3}\right)$

$G_{k}$ : Generation of turbulence kinetic energy due to the mean velocity gradients

$G_{b}$ : Generation of turbulence kinetic energy due to buoyancy

$Y_{k}$ : Contribution of the fluctuating dilatation in compressible turbulence to the overall dissipation rate

$S_{k}$ : User-Defined source terms

$S_{\varepsilon}$ : User-Defined source terms

$C_{1 \varepsilon}$ : An empirical constant equals to 1.44

$C_{2 \varepsilon}:$ An empirical constant equals to 1.92

$C_{3 \varepsilon}:$ An empirical constant equals to 0

$Y_{p}$ : Mass fraction of any product species

$Y_{R}$ : Mass fraction of a particular reactant

$A$ : An empirical constant equals to 4.0

$B$ : An empirical constant equals to 0.5

$T: \quad$ Average temperature in feature section (K)

$\varphi$ : Fuel air ratio

$V:$ Axial velocity $(\mathrm{m} / \mathrm{s})$

$\Gamma$ : $\quad$ Feature parameter.

\section{Acknowledgments}

Hongtao Zheng, Zhibo Zhang, and all the other authors acknowledge the contribution of the staff's advices and also appreciate the authors in the references.

\section{References}

[1] Y. Li, H. Zheng, and L. Cai, "Numerical simulation on hydrogen lean-blowout limit in bluff-body burner," International Journal of Advancements in Computing Technology, vol. 3, no. 10, pp. 232-239, 2011.

[2] M. Stohr, I. Boxx, and C. Carter, "Dynamics of lean blowout of a swirl-stabilized flame in a gas turbine model combustor," Proceedings of the Combustion Institute, vol. 33, pp. 2953-2960, 2011.

[3] W. A. Khan and A. Aziz, "Transient heat transfer in a functionally graded convecting longitudinal fin," Heat and Mass Transfer, vol. 48, no. 10, pp. 1745-1753, 2012.

[4] A. Aziz and W. A. Khan, "Natural convective boundary layer flow of a nanofluid past a convectively heated vertical plate," International Journal of Thermal Sciences, vol. 52, no. 1, pp. 8390, 2012.

[5] O. D. Makinde, T. Chinyoka, and R. S. Lebelo, "Numerical investigation into $\mathrm{CO}_{2}$ emission, $\mathrm{O}_{2}$ depletion, and thermal decomposition in a reacting slab," Mathematical Problems in Engineering, vol. 2011, Article ID 208426, 19 pages, 2011.

[6] O. D. Makinde and T. Chinyoka, "Analysis of unsteady flow of a variable viscosity reactive fluid in a slit with wall suction or injection," Journal of Petroleum Science and Engineering, vol. 9495, pp. 1-11, 2012.
[7] H. C. Mongia, "Recent progress in comprehensive modeling of gas turbine combustion," in Proceedings of the 46th AIAA Aerospace Sciences Meeting and Exhibit, January 2008, AIAA paper no. 2008-1445.

[8] Y.-F. Cui, G. Xu, C.-Q. Nie, and W.-G. Huang, "Application of numerical simulation in the design of gas turbine combustor for burning syngas," Proceedings of the Chinese Society of Electrical Engineering, vol. 26, no. 16, pp. 109-116, 2006.

[9] M. Boileau, G. Staffelbach, B. Cuenot, T. Poinsot, and C. Bérat, "LES of an ignition sequence in a gas turbine engine," Combustion and Flame, vol. 154, no. 1-2, pp. 2-22, 2008.

[10] S. Marinov, M. Kern, K. Merkle et al., "On swirl stabilized flame characteristics near the weak extinction limit," in Proceedings of the ASME Turbo Expo 2010: Power for Land, Sea, and Air, vol. 2, pp. 259-268, June 2010.

[11] T. M. Muruganandam and J. M. Seitzman, "Fluid mechanics of lean blowout precursors in gas turbine combustors," International Journal of Spray and Combustion Dynamics, vol. 4, no. 1, pp. 29-60, 2012.

[12] S. Zhu and S. Acharya, "An experimental study of lean blowout with hydrogen-enriched fuels," Journal of Engineering for Gas Turbines and Power, vol. 134, no. 4, Article ID 041507, 2012.

[13] Y.-X. Yuan, Y.-Z. Lin, and G.-E. Liu, “The effect of flow field and fuel spray of combustor with swirl cup on lean blowout limit in idle condition," Journal of Aerospace Power, vol. 19, no. 3, pp. 332-337, 2004.

[14] Q.-H. Xu, Y.-Z. Lin, G.-E. Liu, and Z.-P. Wang, "Research on the high-temperature rise combustor lean blow-out and smoke emission characteristics," Journal of Aerospace Power, vol. 20, no. 4, pp. 636-640, 2005.

[15] X.-X. Dang, J.-X. Zhao, and H.-H. Ji, "Experimental study of effects of geometric parameters on combustion performance of dual-stage swirler combustor," Journal of Aerospace Power, vol. 22 , no. 10, pp. 1639-1645, 2007.

[16] H.-S. Hu, J.-X. Zhao, J.-P. Zhong, R.-W. Jiang, and M.-Z. Yin, "A new adjustment method of combustor outlet temperature field," Journal of Aerospace Power, vol. 22, no. 8, pp. 1222-1226, 2007.

[17] A. H. Lefebvre and D. R. Ballal Lefebvre, Gas Turbine Combustion: Alternative Fuels and Emissions, CRC Press, New York, NY, USA, 2010.

[18] A. M. Meller, Design of Modern Turbine Combustor, Academic Press, London, UK, 1990.

[19] N. K. Rizk and H. C. Mongia, "A 3d analysis of gas turbine combustor," AIAA paper no. 89-2888, 1989.

[20] H. C. Mongia, "Combining Lefebvre's correlations with combustor CFD," in Proceedings of the 40th AIAA/ASME/SAE/ASEE Joint Propulsion Conference and Exhibit, 2004, AIAA paper no. 2004-3544.

[21] N. K. Rizk and H. C. Mongia, "Gas turbine combustor design methodology," in Proceedings of the 22nd AIAA/ASME/ SAE/ASEE Joint Propulsion Conference, 1986, AIAA paper no. 86-1531.

[22] W.-W. Kim, J. J. Lienau, P. R. van Slooten, M. B. Colket III, R. E. Malecki, and S. Syed, "Towards modeling lean blow out in gas turbine flameholder applications," Journal of Engineering for Gas Turbines and Power, vol. 128, no. 1, pp. 40-48, 2006.

[23] S. J. Shanbhogue, S. Husain, and T. Lieuwen, "Lean blowoff of bluff body stabilized flames: scaling and dynamics," Progress in Energy and Combustion Science, vol. 35, no. 1, pp. 98-120, 2009.

[24] K. Kumaran and U. S. P. Shet, "Effect of swirl on lean flame limits of pilot-stabilized open premixed turbulent flames," Combustion and Flame, vol. 151, no. 1-2, pp. 391-395, 2007. 
[25] Q. Zhang, D. R. Noble, S. J. Shanbhogue, and T. Lieuwen, "Impacts of hydrogen addition on near- lean blowout dynamics in a swirling combustor," in Proceedings of the ASME Turbo Expo 2007: Power for Land, Sea, and Air, pp. 189-198, Montreal, Canada, May 2007, ASME paper no. GT2007-27308.

[26] P. Strakey, T. Sidwell, and J. Ontko, "Investigation of the effects of hydrogen addition on lean extinction in a swirl stablized combustor," Proceedings of the Combustion Institute, vol. 31, no. 2, pp. 3173-3180, 2007.

[27] W.-X. Cai, J.-X. Zhao, H.-S. Hu, X.-X. Dang, and X.-S. Wu, "Numerical prediction of lean blowout in aero-engine combustor," Journal of Aerospace Power, vol. 25, no. 7, pp. 1478-1484, 2010.

[28] K. M. Shebl, "Experimental blowout limits and computational flow field of axial single and multijet flames," Journal of Engineering for Gas Turbines and Power, vol. 130, no. 5, Article ID 054505, 2008.

[29] X. Dang, Experimental investigation and numerical simulation of a gas turbine annular combustor with dual-stage swirler [Dissertation], Nanjing University of Aeronautics and Astronautics, Nanjing, China, 2009.

[30] Z. Qin, V. V. Lissianski, H. Yang, W. C. Gardiner, S. G. Davis, and H. Wang, "Combustion chemistry of propane: a case study of detailed reaction mechanism optimization," Proceedings of the Combustion Institute, vol. 28, no. 2, pp. 1663-1669, 2000.

[31] W. M. Roquemore, R. P. Bradley, J. S. Stutrud, C. M. Reeves, and L. Krishnamurthy, "Preliminary evaluation of a combustor for use in modeling and diagnostics development," ASME paper no. 80-GT-93, 1980.

[32] Y.-X. Yuan, Y.-Z. Lin, G.-E. Liu, G. Hu, and J. Gong, “The effect of fuel-circumferential-staging on lean blowout limit at idle condition," Journal of Aerospace Power, vol. 18, no. 5, pp. 639644, 2003.

[33] Z. Zhang, Experimental study on fuel spray characteristics in model combustor [Dissertation], Nanjing University of Aeronautics and Astronautics, Nanjing, China, 2009.

[34] H.-P. Xu, F. Wang, Y. Huang, and Y.-F. Zhang, "Effects of flow split among swirlers and primary holes on the lean blowoff limits of a combustor with swirl cup," Journal of Aerospace Power, vol. 24, no. 2, pp. 347-352, 2009. 


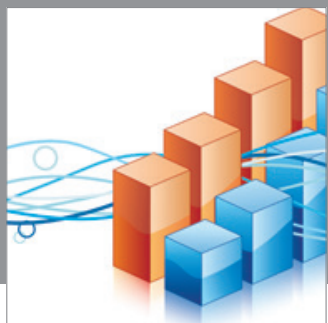

Advances in

Operations Research

mansans

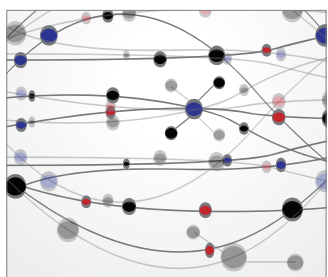

The Scientific World Journal
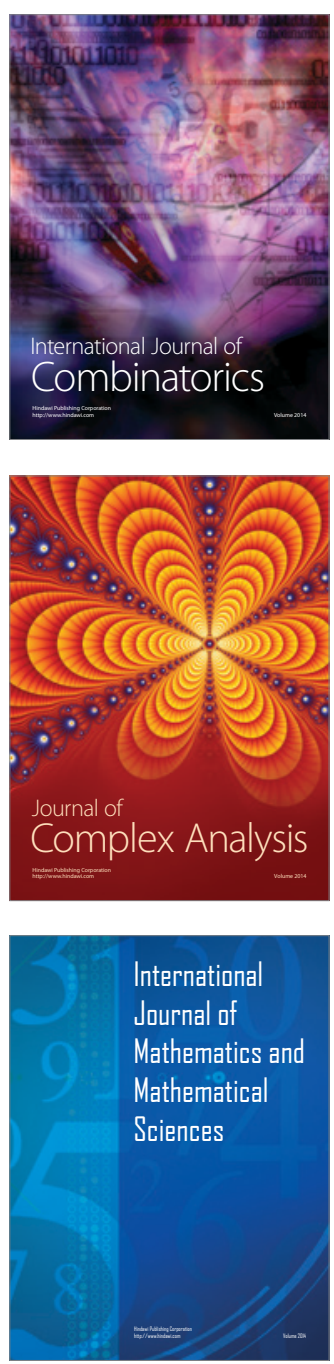
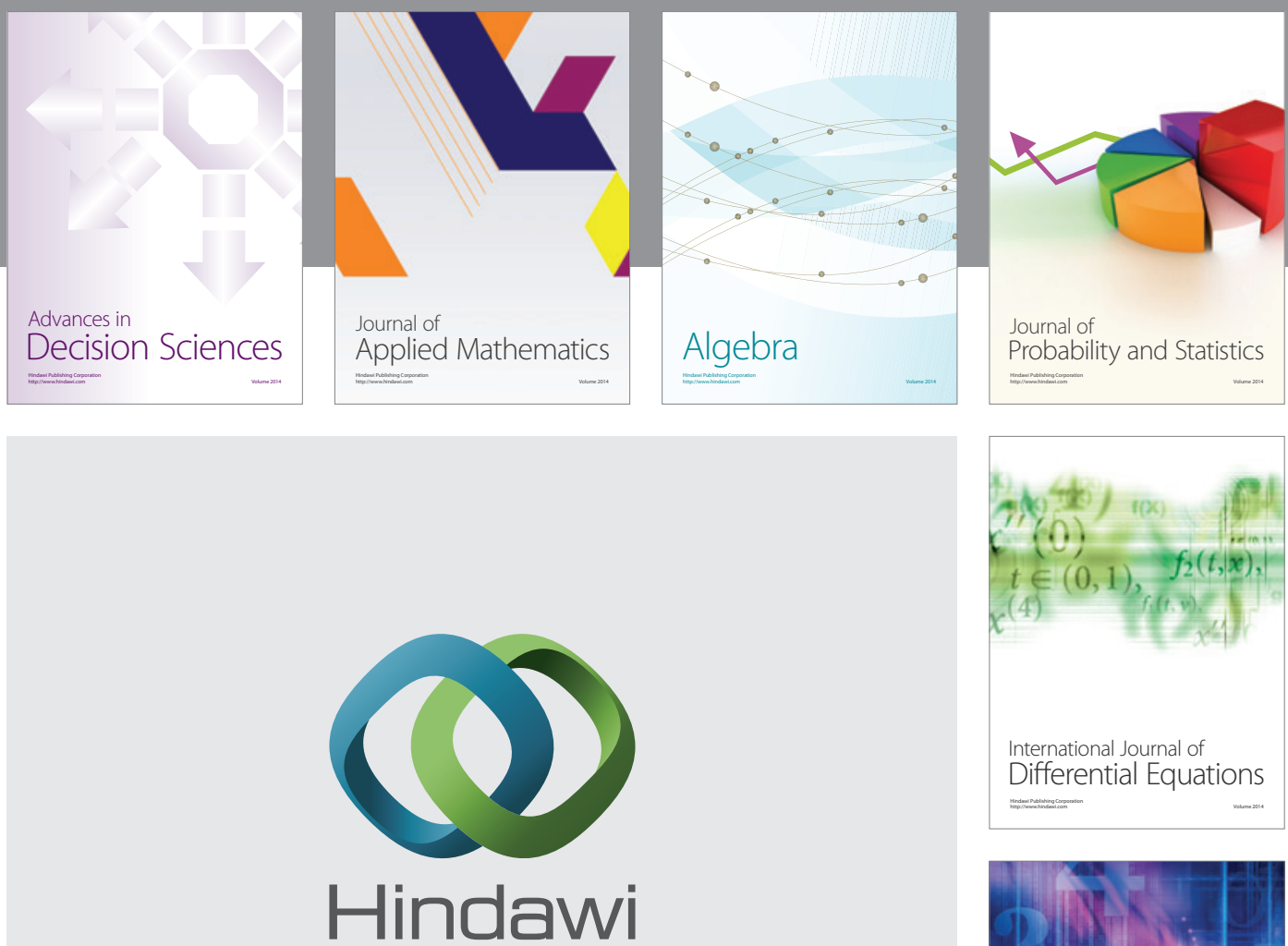

Submit your manuscripts at http://www.hindawi.com
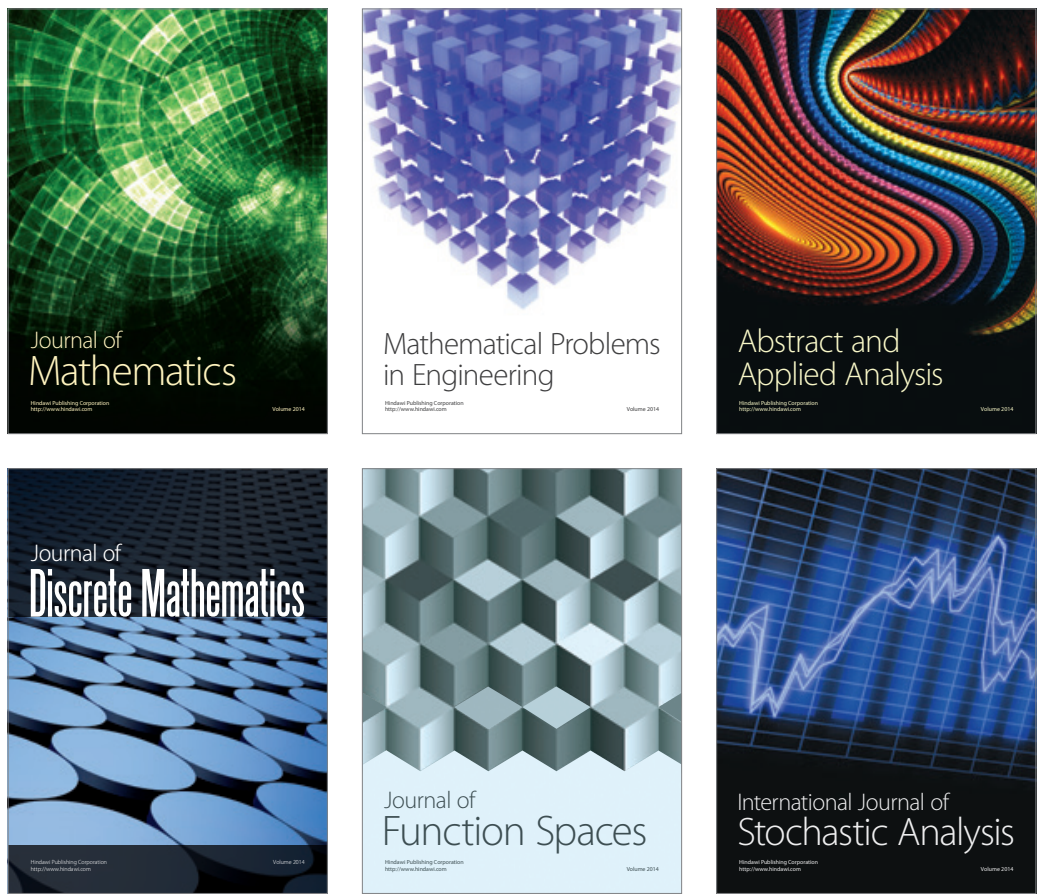

Journal of

Function Spaces

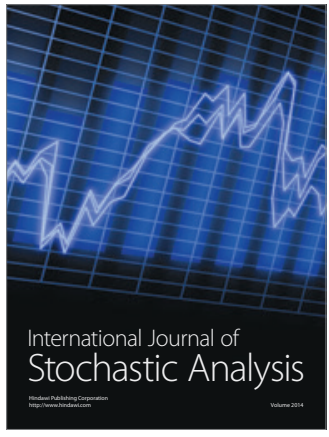

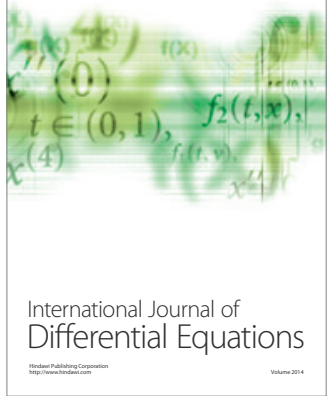
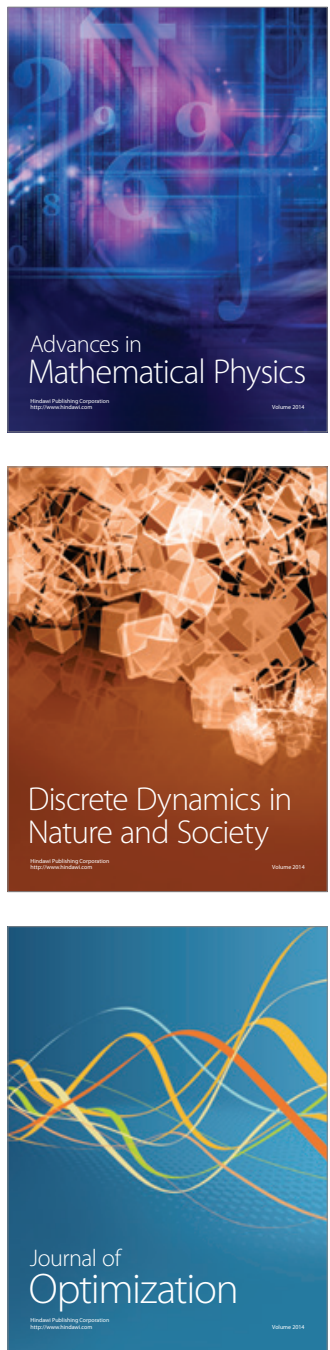